\title{
Pandemic and student mental health: mental health symptoms among university students and young adults after the first cycle of lockdown in the UK
}

Nicole K. Y. Tang, Katharine A. M. McEnery, Laura Chandler, Carla Toro, Lukasz Walasek, Hannah Friend, Sai Gu, Swaran P. Singh and Caroline Meyer

\section{Background}

Early COVID-19 research suggests a detrimental impact of the initial lockdown on young people's mental health

\begin{abstract}
Aims
We investigated mental health among university students and young adults after the first UK lockdown and changes in symp-
\end{abstract} toms over 6 months.

\section{Method}

In total, 895 university students and 547 young adults not in higher education completed an online survey at T1 (JulySeptember 2020). A subset of 201 university students also completed a 6 month follow-up survey at T2 (January-March 2021). Anxiety, depression, insomnia, substance misuse and suicide risk were assessed.

\section{Results}

At T1, approximately $40 \%, 25 \%$ and $33 \%$ of the participants reported moderate to severe anxiety and depression and substance misuse risk, clinically significant insomnia and suicidal risk. In participants reassessed at T2, reductions were observed in anxiety and depression but not in insomnia, substance misuse or suicidality. Student and non-student participants reported similar levels of mental health symptoms. Student status was not a significant marker of mental health symptoms, except for lower substance misuse risk.
Cross-sectionally, greater symptoms across measures were consistently associated with younger age, pre-existing mental health conditions, being a carer, worse financial status, increased sleep irregularity and difficulty since lockdown. Longitudinally, T2 symptoms were consistently associated with worse financial status and increased difficulty sleeping at T1. However, these associations were attenuated when baseline mental health symptoms were adjusted for in the models.

\section{Conclusions}

Mental health symptoms were prevalent in a large proportion of young people after the first UK lockdown. Risk factors identified may help characterise high-risk groups for enhanced support and inform interventions.

\section{Keywords}

University students; young adults; mental health; well-being; COVID-19.

\section{Copyright and usage}

(C) The Author(s), 2022. Published by Cambridge University Press on behalf of the Royal College of Psychiatrists. This is an Open Access article, distributed under the terms of the Creative commons Attribution licence (https://creativecommons.org/ licenses/by/4.0/), which permits unrestricted re-use, distribution, and reproduction in any medium, provided the original work is properly cited.
The impact of COVID-19 restrictions on university students' mental health and well-being during the initial phase of the pandemic has been investigated internationally, with varying rates of clinical problems reported depending on the location, timing and methods of the study. For example, in Guangdong, China, Li et $\mathrm{al}^{1}$ surveyed 164101 university students in February 2020. Using the Patient Health Questionnaire 9 (PHQ-9) and General Anxiety Disorder 7 (GAD-7), the authors reported the prevalence rates of probable clinical depression and anxiety to be $22.4 \%$ and $12.1 \%$. Using the same instruments, higher rates of clinical depression $(48.1 \%)$ and anxiety $(38.5 \%)$ were reported by Wang et $\mathrm{al}^{2}$ in May when they surveyed 2031 students within a large university system in Texas, USA. In France, Wathelet et $\mathrm{al}^{3}$ surveyed 69054 university students between April and May. Using the Beck Depression Inventory-II and the State-Trait Anxiety InventoryState subscale, the prevalence rates of severe depression and anxiety were estimated to be $16.1 \%$ and $27.5 \% .{ }^{4}$ In addition, based on a separate one-item measure, $11.4 \%$ of the student participants reported suicidal thoughts in the past month. The rate of suicidal ideation was comparable to the $12.8 \%$ prevalence reported in a Bangladeshi study that surveyed 3331 university students in the same months ${ }^{4}$ but higher than the $8.2-9.8 \%$ prevalence of suicidal thoughts reported in a UK panel study with 3077 adults. ${ }^{5}$ There are legitimate concerns that pandemics could intensify known triggers of suicide risk in vulnerable groups, ${ }^{5,6}$ resulting in an increase in death by suicide following viral disease outbreaks.

These high rates of depression, anxiety, and suicidal thoughts are thought to be attributable to the lockdown experience and appear responsive to changes in restriction policies. In a UK cohort study, Savage et $\mathrm{al}^{8}$ measured university students' mental well-being twice before (Oct 2019 and Jan 2020) and twice during (March and April 2020) the first UK lockdown. The authors observed a significant decline in self-reported levels of mental well-being, with females reporting lower levels. Evan et $\mathrm{al}^{9}$ found a similar decline in well-being, with over a third of students reporting clinically significant symptoms of depression during the lockdown (April-May 2020), compared with 15\% before. A Polish study ${ }^{10}$ involving 7228 university students over five stages of assessment from March to April 2020 demonstrated a significant increase in depression as the pandemic progressed, particularly when the lockdown involved more pervasive social distancing, isolation and restriction of movement. Interestingly, an Italian study found that students' reported levels of depression rapidly returned to pre-pandemic levels once restrictions were lifted. ${ }^{11}$

Aside from depression, anxiety and suicide risk, there were a number of early COVID studies examining self-reported changes 
in sleep patterns. In a meta-analysis of 44 studies from 13 countries, Jahrami et $\mathrm{al}^{12}$ found that the global pooled prevalence of sleep problems during that pandemic was $35.7 \%$ among the general population. Specifically among university students and staff, an Italian survey found no change in sleep duration, but there were general delays in bedtime and waking time, an increase in time taken to fall asleep, and a worsening of sleep quality and insomnia symptoms during the lockdown. ${ }^{13}$ These changes in sleep timing and quality were more pronounced in females, students and evening-type individuals. There were also unexpected findings from the USA about alcohol/substance use, with reports suggesting the lockdown was associated with an increase in drinking frequency but reductions in the quantity of alcohol consumption, heavy drinking and drunkenness. ${ }^{14}$ Favourable changes were also reported in a French survey of 3671 university students that found reductions in reported binge drinking and tobacco and cannabis use compared with before lockdown. ${ }^{15}$ However, few studies have examined these health behaviours alongside mental health outcomes or identified the common risk factors marking or predicting poor outcomes across the board.

The REsponding to COVID-19 by Enhancing Resilience in Students (RECOVERS) study was set up to investigate mental health among university students and young adults after the first UK lockdown and changes in symptoms over 6 months. It had two components: an online survey and a pilot intervention study. The current study focused on the findings of the survey, which aimed to identify and evaluate characteristics and behaviours that increased the risk of mental health symptoms as the pandemic persisted.

\section{Method}

\section{Study design}

The RECOVERS survey comprised two waves of data collection (Fig. 1). The first occurred between July and September 2020, just after the first UK lockdown and the final university term in the academic year. Unlike studies reported in the existing literature, the RECOVERS survey captured the experiences of participants during this later period of change and uncertainty as they navigated through the fluctuating restriction rules to return to some kind of 'normality'. To explore the longer-term impact of the pandemic on mental health, a second wave of data collection was carried out between January and March 2021. A subgroup of students were surveyed during the third UK lockdown, during the academic spring term, as the vaccination programme was introduced.

Five mental health outcomes were investigated simultaneously at both time points to establish a broader profile of mental health: anxiety, depression, insomnia, substance misuse and suicidality. The baseline survey also examined contextual factors including demographic characteristics, pre-existing health status, study/ work characteristics, risk and exposure to COVID-19, as well as changes in behaviours and circumstances during the pandemic. Changes included adjustments in study time, work hours, financial status, media engagement and sleep behaviours.

The RECOVERS survey examined the prevalence and risk factors of mental health symptoms cross-sectionally and longitudinally, using online questionnaires. The study protocol was informed by the research framework set out by Holmes et $\mathrm{al}^{16}$ and was developed with inputs from university student representatives and the university's well-being service. The authors assert that all procedures contributing to this work comply with the ethical standards of the relevant national and institutional committees on human experimentation and with the Helsinki Declaration of 1975, as revised in 2008. All procedures involving human subjects/patients were approved by the Humanities and Social Sciences Research Ethics Committee of the University of Warwick, UK. All participants provided informed consent prior to starting the online survey. It was made clear in the participant information sheet and at the start of the survey that participants were not obliged to complete all questions. They could close the browser any time, skip any questions or simply choose the 'prefer not to say' option. The participants were not given feedback on their questionnaire scores, as these measures were not designed to give diagnosis. However, a box containing links to helpline information appeared on each page of the questionnaire to ensure those who wanted to seek help could access the relevant services in a timely manner.

The cross-sectional component involved 895 university students (365 from a single university and 530 from other universities) and 547 young adults (aged 18-30 years) not in higher education. All participants completed a survey between July and September 2020 (T1).

The longitudinal component involved a subset of the university student participants recruited from a single university $(n=201)$ completing a 6 month follow-up survey between January and March 2021 (T2).

\section{Participants}

Participants were recruited through two routes. Convenience sampling was used for participant recruitment at a single university, where the study was advertised through university channels. These student participants were not paid to take part in the study, but a prize draw of four $£ 100$ Amazon vouchers was introduced in August 2020 to incentivise participation. Prolific - an online participants recruitment platform - was used to recruit participants from other UK universities and non-student young adults living in the UK. Participants recruited through Prolific were paid the

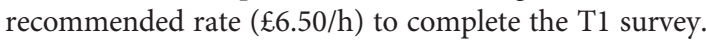

The inclusion criteria for university student participants were to be at least 18 years old and enrolled at a higher education institution in the UK. Non-student participants were required to be between 18 and 30 but not enrolled in full-time university education, forming a broadly 'age-matched' comparison as $92 \%$ of our university student participants fell in this age bracket. The upper age limit of 30 also matched well with the UK public perception of the boundaries of youth. $^{17}$

A subgroup of the student participants who completed the T2 survey were recontacted because they had provided consent to do so. This subsample was drawn from those students recruited from a single university in the UK.

\section{Measures}

The T1 and T2 surveys were identical, except that the T1 survey also asked participants about their demographics, study/work characteristics and pre-existing health status, and included questions on their risk and exposure to COVID-19 and changes in behaviours and circumstances during the first lockdown. In these change questions, participants were asked whether their behaviours and circumstances had increased/were better off, 'stayed the same', or 'decreased/were worse off regarding studies/ work, financial status, physical activity, media engagement and sleep. There were four additional questions on new activities participants had engaged in during the pandemic (making new friends, developing new hobbies, starting new voluntary work and engaging in acts of kindness) for which we asked for a yes or no response. See Tables 3, 6 and 7 for a full variable list. 


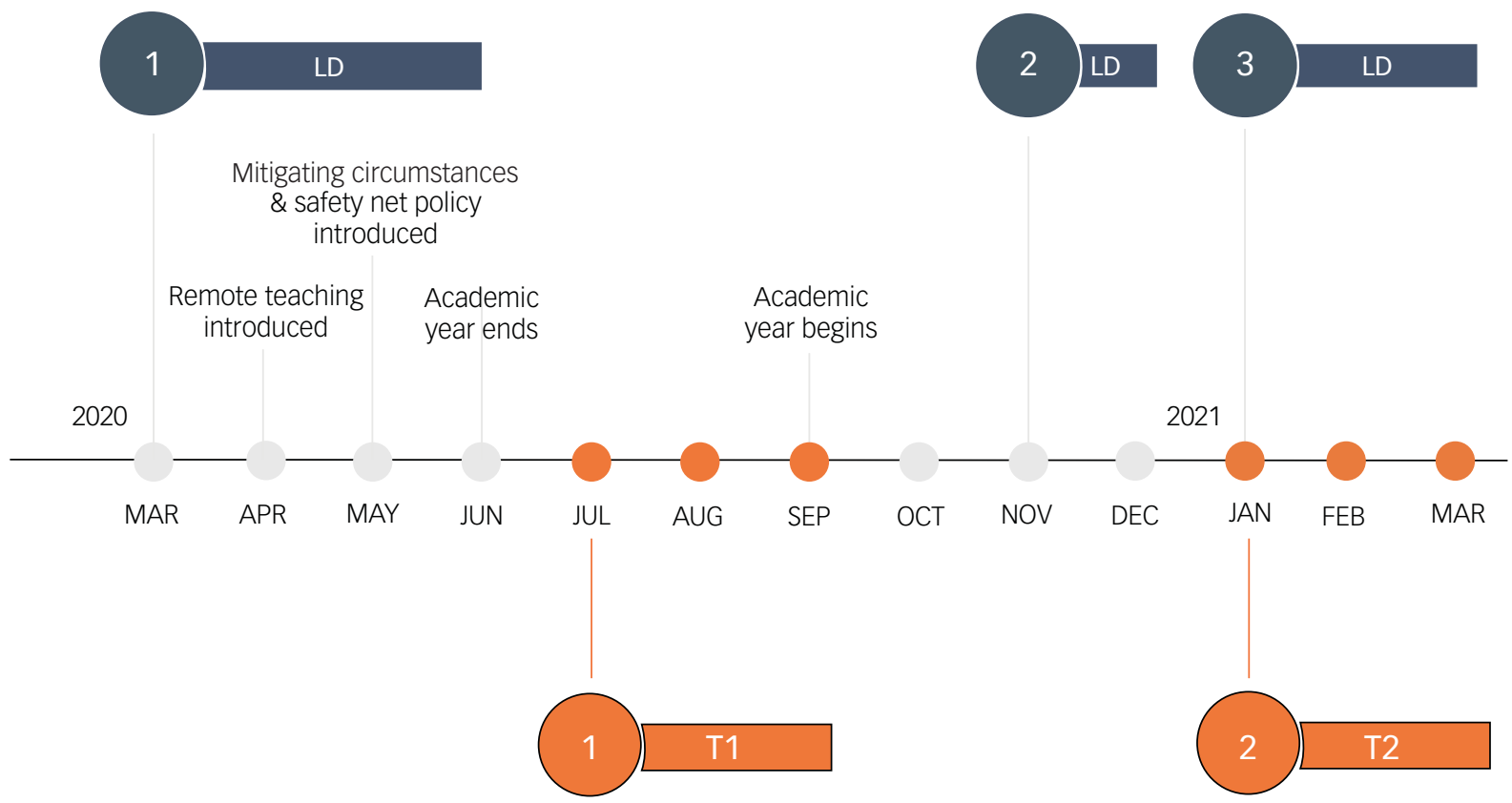

Fig. 1 Timeline of COVID-19 and the Warwick RECOVERS study. Timeline of main events in the UK during the COVID-19 pandemic (lockdowns (LD) 1, 2 and 3), university conditions and time points of RECOVERS data collection. Mitigating circumstances and the safety net policy were university policies put in place to prevent students from being disadvantaged by the alternative teaching and assessment practices that arose from the COVID-19 pandemic. For example, an automatic 2 week deadline extension for assessments in progress (initiated before 13 March 2020) was introduced, and examination boards could be informed of how personal circumstances may have affected the production of research projects and take these circumstances into account when grading work.

\section{Mental health symptoms}

Anxiety

The GAD- $7^{18}$ includes seven Likert scale questions on the frequency of symptoms experienced, which are scored from 0 (not at all) to 3 (nearly every day). A total score of 0-4 indicates no symptoms, 5-9 mild symptoms, 10-14 moderate symptoms and 15-21 severe symptoms.

\section{Depression}

The PHQ- $9^{18}$ asks nine Likert scale questions on the frequency of symptoms experienced, which are scored from 0 (not at all) to 3 (nearly every day). Total scores are categorised: 0-4 no symptoms, 5-9 mild symptoms, 10-14 moderate symptoms, 15-19 moderately severe symptoms and 20-27 severe symptoms.

Insomnia

The Insomnia Severity Index (ISI- 3$)^{19}$ includes three questions on sleep satisfaction, worry about sleep and how sleep interferes with daily functioning. Each question is scored between 0 (very satisfied, not at all worried/interfering) and 4 (very dissatisfied, very much worried/interfering). A total score of 7-12 indicates clinical insomnia.

\section{Substance misuse}

The National Institute of Drug Abuse Alcohol Smoking Substance Involvement Screening Test (NIDA-ASSIST) ${ }^{20}$ includes seven Likert scale questions on the frequency and impact of use for four substances: alcohol, tobacco, prescription medication and other substances. Each question is weighted differently depending on the severity of the risk examined by the item: for example, the item asking participants 'how often have you failed to do what was normally expected of you because of your use of [first drug, second drug, etc.]' is weighted more heavily than the question 'In the past three months, how often have you used the substances you mentioned [first drug, second drug, etc.]?'. The average total score for all substances was used to evaluate risk: low risk (0-3.49), moderate risk (3.5-26.49) and high risk (26.5-39).

\section{Suicidality}

The Suicide Behaviours Questionnaire - Revised (SBQ-R) ${ }^{21}$ includes four questions to assess different dimensions of suicidality: lifetime suicide ideation/attempt, frequency of suicide ideation/ attempt, threat of suicide attempt and future suicidal behaviour. The total score ranges from 3 to 18 , and a cut-off score of $\geq 7$ is recommended for use in non-clinical samples.

\section{Analysis}

Statistical analyses were performed using SPSS $27{ }^{22}$

\section{Handling of missing data and incomplete survey submission}

A total of 1442 participants completed the T1 survey. As the survey was online, not all responses were complete (defined as surveys returned by participants who provided informed consent and engaged with the questionnaire until the very end). The survey completion rate was high $(78 \%)$ among participants recruited from Prolific. However, of the participants who were recruited using convenience sampling, 716 started the survey but only 428 (60\%) completed and returned the survey.

As part of the data preparation, chi-squared tests and $t$-tests were conducted to examine any differences in demographics between groups of participants who did and did not complete the baseline survey. There were no significant differences in gender composition between completers and non-completers, but there were higher rates of incomplete surveys among those returned by participants who were younger and self-identified as Asian/Asian British, Black/African/Caribbean/Black British or of other ethnicity (Supplementary Table 1 available at https://doi.org/10.1192/bjo. 
2022.523). At 6 months, there were also higher rates of incomplete surveys among those returned by participants who self-identified as Asian/Asian British, Black/African/Caribbean/Black British, or of mixed or other ethnicity. However, no significant differences were detected for age, gender or any of the baseline mental health outcome measures (Supplementary Table 2).

To counteract potential biases introduced through attrition (i.e. non-completion of surveys), stabilised inverse propensity scores were applied in analyses as weights. ${ }^{23,24}$ The propensity score referred to the conditional probability of being a completer of the survey and was calculated using three key demographic variables (age, gender and ethnicity) of all survey starters. The inverse of the propensity score was then multiplied by the marginal probability of being a survey completer. The resultant stabilised inverse probability weights (SIPW) help to balance biases introduced through attrition; this approach has the advantage of preserving the sample size of the original data and minimising the type I error rate in the estimation of variances of main effects. Two SIPWs were calculated: one for baseline and one for 6 month follow-up.

Unweighted and weighted analyses were performed with data from those who completed the entire survey. Weighted beta-coefficients and statistical significance were reported for all regression analyses. Unweighted descriptive statistics (percentages of selfreported changes in behaviours and circumstances) are presented in Figs 1 and 2 and the demographic variables of T2 participants shown in Table 4 for easy interpretation.

\section{Cross-sectional analysis}

To characterise and detect differences between groups (students and non-students), $t$-tests or chi-squared tests were conducted to compare all relevant variables. Means and standard deviations were reported for continuous variables and frequencies and percentages for categorical variables.

Regression analysis was conducted using T1 survey data. Five sets of analysis were carried out for the five mental health symptoms of interest (i.e. total scores on GAD-7, PHQ-9, ISI-3, NIDA-ASSIST and SBQ-R).

We had 45 possible predictors that could be included in the full regression model, but given the sample size of 1442 for the crosssectional analysis and 201 for the longitudinal analysis (described in the next section), we ran univariate regression models for each individual predictor (model 1) and only included those that were significant at $P<0.05$ in our multivariate models (model 2), to avoid overfitting. ${ }^{25}$

In model 2 for each set of analysis, significant univariate predictors were entered in blocks in the following order: group (students or non-students) and demographic characteristics (block 1), COVID-19 risk and exposure (block 2), and changes in behaviour and circumstance since lockdown (block 3). This allowed us to determine the specific risk(s) to young people's mental health associated with studying at university and to examine the role of changes in behaviours and circumstances due to COVID, controlling for demographics and COVID-19 risk and exposure, which were less amenable to change.

\section{Longitudinal analysis}

Changes in mental health symptoms over time were analysed using available data provided by student participants who completed both T1 and T2 surveys. Paired $t$-tests and chi-squared tests were used to detect these changes.

Longitudinal regression analysis was conducted using the same approach as that used for the cross-sectional analysis, but the outcomes predicted were total scores on GAD-7, PHQ-9, ISI-3, NIDA-ASSIST and SBQ-R at T2. We had a total of 50 possible predictors that could be included in the full regression model. Again, we ran univariate regression models for each individual predictor (model 1) and only included those that were significant at $P<0.05$ in our multivariate models (model 2), to avoid overfitting. ${ }^{25}$ In model 2 for each set of analysis, significant univariate predictors were entered in blocks in the following order: demographic characteristics (block 1), study characteristics (block 2), COVID-19 risk and exposure (block 3 ), and changes in behaviour and circumstance since lockdown (block 4). In addition to models 1 and 2, a model 3 was used for each set of analysis to include the respective score at T1 as a predictor, to further adjust for baseline status.

\section{Results}

\section{Participant characteristics and comparisons between students and non-students}

Students sampled were predominantly UK domestic students (56\%), followed by EU (26\%) and other international students (16\%); only $1.7 \%$ of students sampled were visiting students. At T1, $70 \%$ of students were undergraduate and $29 \%$ were postgraduate students, and most students sampled were in full-time education (86\%). Few students were living on campus before lockdown (30\%); after lockdown, even fewer were still on campus (14.5\%). Of students sampled, $52 \%$ had exams in 2020, 25\% did not have exams and $24 \%$ said they were given alternative assessments.

As presented in Table 1, the student and non-student groups shared similarities with respect to many aspects measured, but they differed in age, ethnicity and current location, with the student sample being younger, more diverse and more international compared with the non-student sample. Students were living in larger groupings and a greater proportion of them were living with friends or housemates than non-students, who more often were living with partners. Related to this, students also reported higher exposure to COVID-19 cases in their extended family and social network than non-students. Although no difference was observed in pre-existing physical condition(s) reported, a larger proportion of non-students reported moderate COVID-19 risk as defined by the UK government and a pre-existing mental health condition compared with students.

\section{Self-reported changes in behaviour and circumstances at T1}

Figure 2 depicts the changes in behaviours and circumstances reported by participants, and Fig. 3 shows the percentages of reported new/positive activities. In Fig. 2, the positive y-axis represents the percentage increase/improvement and the negative y-axis represents percentage decrease/worsening. Only changes are presented; the percentage that stayed the same for each category of behaviour or circumstances was not shown. Overall, there were greater percentages of both student and non-student participants reporting a reduction in study hours/engagement, work hours, financial status and physical activity since the first lockdown, compared with an increase/improvement in these aspects. Within both groups, the majority of the participants reported an increase in media engagement, including news usage and social media use for general browsing and socialising. For the sleep questions, more participants reported an increase in sleep duration but a reduction in sleep quality. There were also more participants reporting going to bed at a later time than usual and having difficulty sleeping but not necessarily a more irregular sleep pattern. Engagement in new/positive activities was reported, with between 20 and $32 \%$ reported having engaged in acts of kindness and between 37 and $51 \%$ reporting picking up new hobbies since the lockdown.

There were significant differences between student and nonstudent participants in these reported changes in 9 out of 12 


\begin{tabular}{|c|c|c|c|c|c|c|c|c|}
\hline \multirow[b]{2}{*}{ Variable } & \multicolumn{2}{|c|}{ Students } & \multicolumn{2}{|c|}{ Non-students } & \multicolumn{2}{|c|}{ Total } & \multirow[b]{2}{*}{ Comparison $t$ or $\chi^{2}$} & \multirow{2}{*}{$\begin{array}{c}\text { Weighted } \\
\text { comparison } t \text { or } \chi^{2}\end{array}$} \\
\hline & Mean, $n$ & s.d., \% & Mean, $n$ & s.d., \% & Mean, $n$ & s.d., \% & & \\
\hline Age, years & 23.4 & 6.4 & 27.2 & 4.7 & 25.4 & 20.7 & $\begin{array}{c}\boldsymbol{t}=-12.07^{* * *} \\
\boldsymbol{\chi}^{2}=301.78^{\star * *}\end{array}$ & $\begin{array}{l}-11.61^{* * *} \\
260.20^{* * *}\end{array}$ \\
\hline 20 or under & 311 & 34.8 & 65 & 11.9 & 376 & 26.1 & & \\
\hline $21-24$ & 360 & 40.3 & 97 & 17.7 & 457 & 31.7 & & \\
\hline $25-29$ & 143 & 16.0 & 188 & 34.4 & 331 & 23.0 & & \\
\hline 30 or over & 80 & 8.9 & 197 & 36.0 & 277 & 19.2 & & \\
\hline Total & 894 & 100 & 547 & 100 & 1441 & 100 & & \\
\hline Gender & & & & & & & $\chi^{2}=0.61$ & 0.37 \\
\hline Female & 498 & 55.6 & 313 & 57.2 & 811 & 56.2 & & \\
\hline Male & 382 & 42.7 & 227 & 41.5 & 609 & 42.2 & & \\
\hline Other & 15 & 1.7 & 7 & 1.3 & 22 & 1.5 & & \\
\hline Total & 895 & 100 & 547 & 100 & 1442 & 100 & & \\
\hline Ethnicity & & & & & & & $\chi^{2}=98.54^{\star \star *}$ & $89.13^{* * *}$ \\
\hline White/Caucasian & 624 & 69.9 & 501 & 91.6 & 1125 & 78.1 & & \\
\hline African/Caribbean/ Black British & 42 & 4.7 & 10 & 1.8 & 52 & 3.6 & & \\
\hline Asian/Asian British & 150 & 16.8 & 17 & 3.1 & 167 & 11.6 & & \\
\hline Mixed & 54 & 6.0 & 17 & 3.1 & 71 & 4.9 & & \\
\hline Other & 23 & 2.6 & 2 & 0.4 & 25 & 1.7 & & \\
\hline Total & 893 & 100 & 547 & 100 & 1442 & 100 & & \\
\hline Current location & & & & & & & $\chi^{2}=135.71^{\star * *}$ & $111.93 * * *$ \\
\hline UK & 595 & 66.5 & 510 & 93.2 & 1105 & 76.6 & & \\
\hline Non-UK & 300 & 33.5 & 37 & 6.8 & 337 & 23.4 & & \\
\hline Total & 895 & 100 & 547 & 100 & 1442 & 100 & & \\
\hline Current household members ${ }^{\mathrm{a}, \mathrm{b}}$ & & & & & & & $\chi^{2}=28.28^{* \star *}$ & $25.97 * * *$ \\
\hline Family & 662 & 80.2 & 418 & 83.3 & 1080 & 81.4 & & \\
\hline Friend/housemates & 91 & 11.0 & 20 & 4 & 111 & 8.4 & & \\
\hline Partners & 56 & 6.8 & 60 & 12.0 & 116 & 8.7 & & \\
\hline Other & 16 & 2 & 4 & 0.8 & 20 & 1.6 & & \\
\hline Total5 & 825 & 100 & 502 & 100 & 1327 & 100 & & \\
\hline Current household size $^{a}$ & & & & & & & $x^{2}=29.21 * * *$ & $25.23^{* * *}$ \\
\hline Alone & 70 & 7.8 & 45 & 8.2 & 115 & 8.0 & & \\
\hline 1-2 other people & 351 & 39.2 & 292 & 53.4 & 643 & 44.6 & & \\
\hline 3+ other people & 466 & 52.1 & 209 & 38.2 & 675 & 46.8 & & \\
\hline Other & 8 & 0.9 & 1 & 0.2 & 9 & 0.6 & & \\
\hline Total & 895 & 100 & 547 & 100 & 1442 & 100 & & \\
\hline Physical health condition ${ }^{c}$ & & & & & & & $\chi^{2}=2.60$ & 0.01 \\
\hline Yes & 168 & 18.8 & 104 & 19.0 & 272 & 18.9 & & \\
\hline No & 709 & 79.2 & 438 & 80.1 & 1147 & 79.5 & & \\
\hline Other & 18 & 2.0 & 5 & 0.9 & 23 & 1.6 & & \\
\hline Total & 895 & 100 & 547 & 100 & 1442 & 100 & & \\
\hline Mental health condition ${ }^{c}$ & & & & & & & $x^{2}=22.16^{* * *}$ & $16.59 * * *$ \\
\hline Yes & 210 & 23.5 & 289 & 34.6 & 399 & 27.7 & & \\
\hline No & 656 & 73.3 & 348 & 63.6 & 1004 & 69.6 & & \\
\hline Other & 29 & 3.2 & 10 & 1.8 & 39 & 2.7 & & \\
\hline Total & 895 & 100 & 547 & 100 & 1442 & 100 & & \\
\hline Using a health tracker app ${ }^{a}$ & & & & & & & $\chi^{2}=0.85$ & 0.65 \\
\hline Yes & 319 & 35.6 & 210 & 38.4 & 529 & 36.7 & & \\
\hline No & 566 & 63.2 & 336 & 61.4 & 902 & 62.6 & & \\
\hline Other & 10 & 1.1 & 1 & 0.2 & 11 & 0.8 & & \\
\hline Total & 895 & 100 & 547 & 100 & 1442 & 100 & & \\
\hline Carer status $^{a}$ & & & & & & & $\chi^{2}=0.11$ & 0.02 \\
\hline Yes & 106 & 11.8 & 62 & 11.3 & 168 & 11.7 & & \\
\hline No & 779 & 87.0 & 482 & 88.1 & 1261 & 87.4 & & \\
\hline Other & 10 & 1.1 & 3 & 0.5 & 13 & 0.9 & & \\
\hline Total & 895 & 100 & 547 & 100 & 1442 & 100 & & \\
\hline Sleep chronotype & & & & & & & $\chi^{2}=0.37$ & 0.29 \\
\hline Morning lark & 206 & 23.0 & 133 & 24.3 & 339 & 23.5 & & \\
\hline Night owl & 469 & 52.4 & 279 & 51.0 & 748 & 51.9 & & \\
\hline Other & 220 & 24.5 & 135 & 24.7 & 345 & 24.6 & & \\
\hline Total & 895 & 100 & 547 & 100 & 1442 & 100 & & \\
\hline COVID-19 high risk a,d & & & & & & & $\chi^{2}=1.41$ & 0.95 \\
\hline Yes & 27 & 3.0 & 23 & 4.2 & 50 & 3.5 & & \\
\hline No & 862 & 96.5 & 522 & 95.4 & 1384 & 96.1 & & \\
\hline Other & 4 & 0.4 & 2 & 0.4 & 6 & 0.4 & & \\
\hline Total & 893 & 100 & 547 & 100 & 1440 & 100 & & \\
\hline COVID-19 moderate risk & & & & & & & $\chi^{2}=1.47^{* * * *}$ & $10.53^{* * * *}$ \\
\hline Yes & 98 & 11.0 & 95 & 17.4 & 193 & 13.4 & & \\
\hline No & 785 & 87.9 & 451 & 82.4 & 1236 & 85.8 & & \\
\hline Other & 10 & 1.1 & 1 & 0.2 & 11 & 0.8 & & \\
\hline Total & 893 & 100 & 547 & 100 & 1440 & 100 & & \\
\hline
\end{tabular}




\begin{tabular}{|c|c|c|c|c|c|c|c|c|}
\hline \multirow[b]{2}{*}{ Variable } & \multicolumn{2}{|c|}{ Students } & \multicolumn{2}{|c|}{ Non-students } & \multicolumn{2}{|c|}{ Total } & \multirow[b]{2}{*}{ Comparison $t$ or $\chi^{2}$} & \multirow{2}{*}{$\begin{array}{c}\text { Weighted } \\
\text { comparison } t \text { or } \chi^{2}\end{array}$} \\
\hline & Mean, $n$ & s.d., \% & Mean, $n$ & s.d., \% & Mean, $n$ & s.d., \% & & \\
\hline \multicolumn{7}{|l|}{ Tested positive for COVID-19a } & \multirow[t]{5}{*}{$\chi^{2}=0.99$} & \multirow[t]{5}{*}{1.00} \\
\hline Yes & 8 & 0.9 & 8 & 1.5 & 16 & 1.1 & & \\
\hline No & 884 & 98.8 & 538 & 98.4 & 1422 & 98.6 & & \\
\hline Other & 3 & 0.3 & 1 & 0.2 & 4 & 0.3 & & \\
\hline Total & 895 & 100 & 547 & 100 & 1442 & 100 & & \\
\hline \multicolumn{7}{|l|}{ Tested positive for COVID-19 (family/friends) ${ }^{a}$} & \multirow[t]{5}{*}{$\chi^{2}=0.79$} & \multirow[t]{5}{*}{0.55} \\
\hline Yes & 100 & 11.2 & 70 & 12.8 & 170 & 11.8 & & \\
\hline No & 790 & 88.3 & 477 & 87.2 & 1267 & 87.9 & & \\
\hline Other & 5 & 0.6 & 0 & 0 & 5 & 0.3 & & \\
\hline Total & 895 & 100 & 547 & 100 & 1442 & 100 & & \\
\hline \multicolumn{7}{|c|}{ Tested positive for COVID-19 (Extended family/social network) ${ }^{\mathrm{a}}$} & \multirow[t]{5}{*}{$\chi^{2}=10.56^{* * * *}$} & \multirow[t]{5}{*}{$9.15^{\star * \star *}$} \\
\hline Yes & 302 & 33.7 & 141 & 25.8 & 443 & 30.7 & & \\
\hline No & 585 & 65.4 & 404 & 73.9 & 989 & 68.6 & & \\
\hline Other & 8 & 0.9 & 2 & 0.4 & 10 & 0.7 & & \\
\hline Total & 895 & 100 & 547 & 100 & 1442 & 100 & & \\
\hline \multicolumn{9}{|c|}{$\begin{array}{l}\text { Unweighted frequency, percentage and } \chi^{2} \text { are reported for all variables except age, for which mean, standard deviation and } t \text { are reported also. Weighted comparisons are reported in the } \\
\text { final column on the right. } \\
\text { f**P } 20.01,{ }^{* * * *} P<0.001 \text {. } \\
\text { a. } \chi^{2} \text { was calculated without the 'other' category, because including this category violated } \chi^{2} \text { assumptions as two cells had expected count less than } 5 \text {. } \\
\text { b. Excluding those who answered 'living alone' in the current household size question. } \\
\text { c. Physical health problem and mental health problem refer specifically to diagnosed conditions. } \\
\text { d. High risk: as defined by the UK government regulation - received bone marrow or stem cell transplant in the past } 6 \text { months, or are still taking immunosuppressant medicine, received an } \\
\text { organ transplant, severe lung condition (such as cystic fibrosis, severe asthma or severe chronic obstructive pulmonary disease (COPD)), having chemotherapy or antibody treatment for } \\
\text { cancer, including immunotherapy, have a condition that means a very high risk of getting infections (such as severe combined immunodeficiency (SCID) or sickle cell), having an intense } \\
\text { course of radiotherapy (radical radiotherapy) for lung cancer, taking medicine that makes them much more likely to get infections (such as high doses of steroids), having targeted cancer } \\
\text { treatments that can affect the immune system (such as protein kinase inhibitors or PARP inhibitors), have a serious heart condition and are pregnant, had blood or bone marrow cancer (such } \\
\text { as leukaemia, lymphoma or myeloma). } \\
\text { e. Moderate risk: as defined by the UK government regulation - have liver disease (such as hepatitis), age } 70 \text { or older, have a condition affecting the brain or nerves (such as Parkinson's } \\
\text { disease, motor neurone disease, multiple sclerosis or cerebral palsy), pregnant, have a condition that means a high risk of getting infections, have a lung condition that is not severe (such as } \\
\text { asthma, COPD, emphysema or bronchitis), taking medicine that can affect the immune system (such as low doses of steroids), have heart disease (such as heart failure), very obese (body } \\
\text { mass index of } 40 \text { or above), have diabetes, have chronic kidney disease. }\end{array}$} \\
\hline
\end{tabular}

100

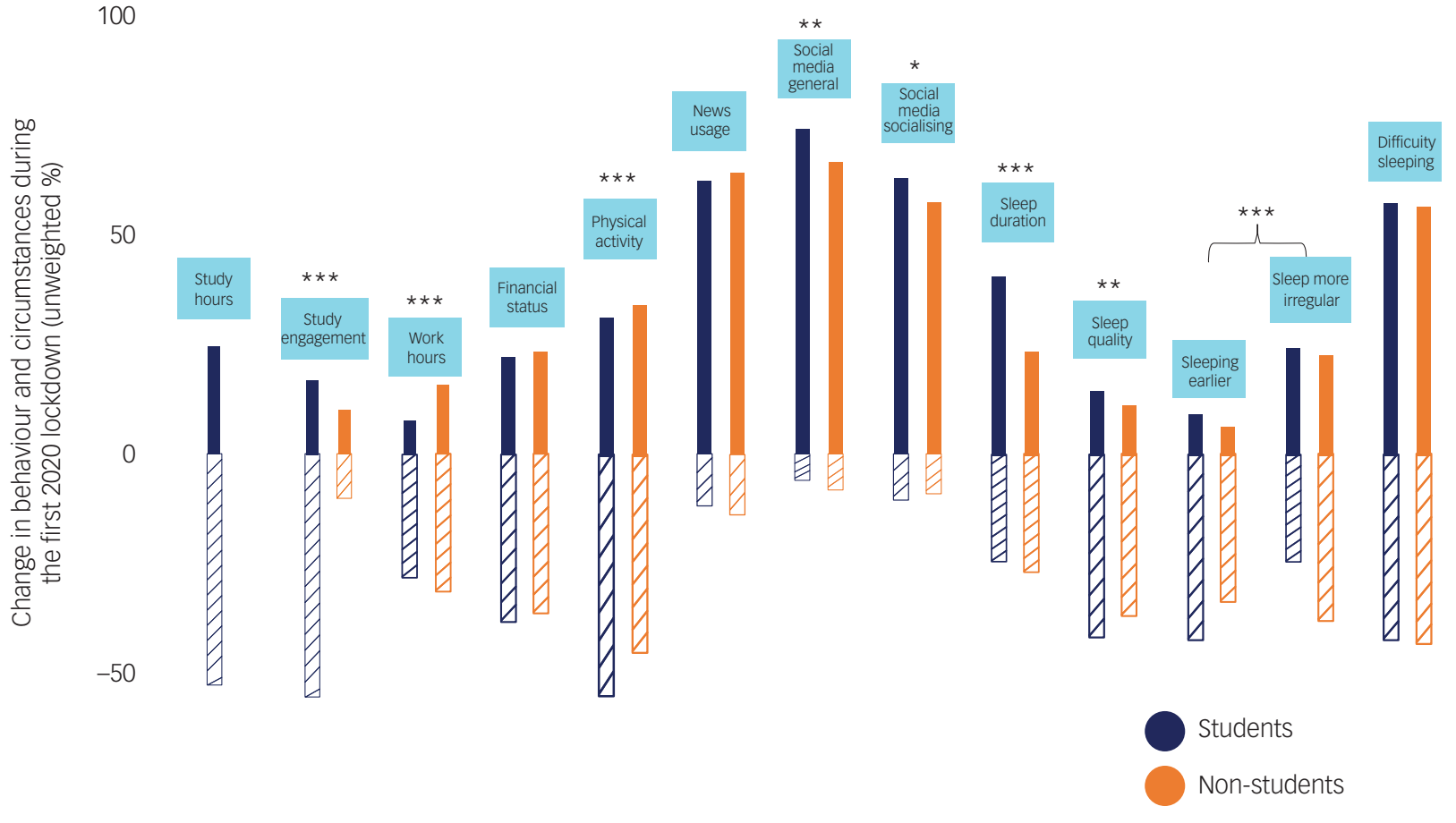

Fig. 2 Changes in behaviours and circumstances since the lockdown at T1. The positive $y$-axis represents the percentage increase/improved and the negative $y$-axis represents percentage decrease/worsened. For sleeping earlier, the negative $y$-axis represents the percentage of participants who reported sleeping later. For sleep more irregular, the negative $y$-axis represents the percentage of participants who reported that their sleep pattern stayed the same. For difficulty sleeping, the negative $y$-axis represents the percentage of participants who reported not having difficulty sleeping. Only unweighted percentages are presented for easy interpretation, as weighted percentages were almost identical and the pattern of differences revealed by chi-squared $\left(\chi^{2}\right)$ tests are the same. Only one $\chi^{2}$ was conducted for sleeping earlier and sleep more irregular as these were extracted from the same question, with four response options on changes in sleeping patterns ('going to sleep at an earlier time than is usual for you', 'going to sleep at a later time than is usual for you', 'lost its regularity' and 'stayed about the same'). ${ }^{*} P<0.05$, ${ }^{* *} P<0.01,{ }^{* * *} P<0.001$ 
90

80

40

10
10

0

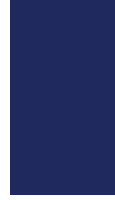

Made new

friends
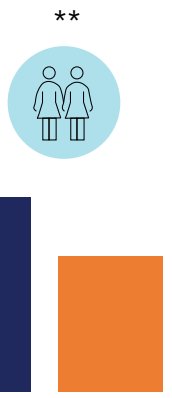

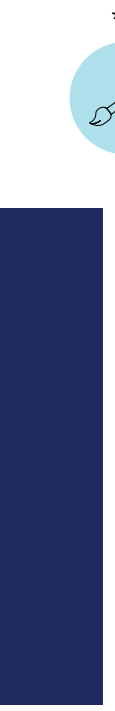

$\star \star \star$

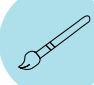

Picked up new hobbies

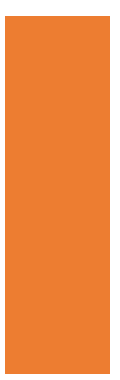

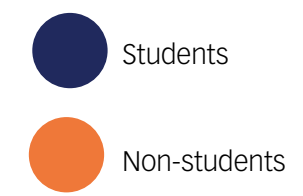

Non-students

Fig. 3 New/positive activities engagement since the lockdown at T1. Graph reporting the percentage of participants, by group, who engaged in the featured new/positive activities since the first lockdown. Only unweighted percentages are presented for easy interpretation, as weighted percentages were almost identical and the pattern of differences revealed by chi-squared tests were the same. ${ }^{*} P<0.05,{ }^{* *} P<0.01,{ }^{* *} P<$ 0.001 .

behaviours or circumstances and engagement in three out of four new/positive activities.

\section{Mental health symptoms at T1}

Based on responses to the GAD-7, PHQ-9, ISI-3, NIDA-ASSIST and SBQ-R (Table 2), just over $40 \%$ of participants reported moderate to severe symptoms of anxiety and depression, $25 \%$ reported clinically significant insomnia, 35\% reported moderate to high risk of substance misuse and 33\% reported clinically significant suicidal risk.

There were no significant differences between student and nonstudent participants in their levels of anxiety, depression, insomnia and suicidality at $\mathrm{T} 1$, with the exception of substance misuse risk. The mean NIDA-ASSIST score was higher among non-student than student participants. The proportions of participants reporting moderate risk of substance misuse or severe depression were higher for non-student compared with student participants.

\section{Risk markers of mental health symptoms at T1}

Table 3 shows regression coefficients of all risk markers included in model 2 for all five mental health outcome measures.

\section{Anxiety}

The significant risk markers of anxiety were younger age, having a previously diagnosed mental health condition, being a carer, worse financial status, more irregular sleep pattern and increased difficulty sleeping. The co-efficient of determination $\left(\mathrm{R}^{2}\right)$ for model 2 was 0.280 .

\section{Depression}

The significant risk markers of depression were younger age, having a previously diagnosed mental health condition, being a carer, reduced physical activity, worse financial status, more irregular sleep pattern and increased difficulty sleeping. The $\mathrm{R}^{2}$ for model 2 was 0.314 .

\section{Insomnia}

The significant risk markers of insomnia were having a previously diagnosed mental health condition, using a health tracker app, being a carer, more irregular sleep pattern and increased difficulty sleeping. The $\mathrm{R}^{2}$ for model 2 was 0.673 .

\section{Substance misuse}

The significant risk markers of substance misuse were not being a student, gender (not female), ethnically not Asian/Asian British, not currently in the UK, living with friends or housemates, having a previously diagnosed mental health condition, having tested positive for COVID-19, worse financial status and more irregular sleep pattern. The $\mathrm{R}^{2}$ for model 2 was 0.114 .

\section{Suicidality}

The significant risk markers of suicidality were younger age, gender (other), having a previously diagnosed mental health condition, worse financial status and increased difficulty sleeping. The $\mathrm{R}^{2}$ for model 2 was 0.260 . 


\begin{tabular}{|c|c|c|c|c|c|c|c|c|}
\hline \multirow[b]{2}{*}{ Variable } & \multicolumn{2}{|c|}{ Students } & \multicolumn{2}{|c|}{ Non-students } & \multicolumn{2}{|c|}{ Total } & \multirow[b]{2}{*}{ Comparison $t$ or $\chi^{2}$} & \multirow{2}{*}{$\begin{array}{c}\text { Weighted } \\
\text { Comparison } t \text { or } \chi^{2}\end{array}$} \\
\hline & Mean, $n$ & s.d., \% & Mean, $n$ & s.d., \% & Mean, $n$ & s.d., \% & & \\
\hline \multicolumn{9}{|l|}{ GAD-7 } \\
\hline Mean $(95 \%$ Cl) & $8.47(8.1-8.9)$ & 5.93 & $8.66(8.1-9.2)$ & 6.20 & $8.4(8.2-8.9)$ & 6.03 & $\boldsymbol{t}=-0.56$ & -0.53 \\
\hline None & 277 & 31.0 & 173 & 31.6 & 450 & 31.3 & $\chi^{2}=2.40$ & 2.20 \\
\hline Mild & 252 & 28.2 & 147 & 26.9 & 399 & 27.7 & & \\
\hline Moderate & 197 & 22.1 & 109 & 19.9 & 306 & 21.3 & & \\
\hline Severe & 167 & 18.7 & 118 & 21.6 & 285 & 19.8 & & \\
\hline Total & 893 & 100 & 547 & 100 & 1440 & 100 & & \\
\hline \multicolumn{9}{|l|}{ PHQ-9 } \\
\hline Mean $(95 \% \mathrm{Cl})$ & 8.93 (8.5-9.3) & 6.06 & $9.6(9.0-10.2)$ & 6.84 & 9.18 (8.9-9.5) & 6.37 & $\boldsymbol{t}=-1.88$ & -1.77 \\
\hline None & 249 & 27.9 & 167 & 30.6 & 416 & 28.9 & $\chi^{2}=14.76^{\star \star *}$ & $13.04^{* *}$ \\
\hline Mild & 284 & 31.8 & 130 & 23.8 & 414 & 28.7 & & \\
\hline Moderate & 177 & 19.8 & 111 & 20.3 & 288 & 20.0 & & \\
\hline Moderately Severe & 130 & 14.5 & 85 & 15.6 & 215 & 14.9 & & \\
\hline Severe & 54 & 6.0 & 53 & 9.7 & 107 & 7.4 & & \\
\hline Total & 894 & 100 & 546 & 100 & 1440 & 100 & & \\
\hline \multicolumn{9}{|l|}{ ISI-3 } \\
\hline Mean $(95 \% \mathrm{Cl})$ & $3.63(3.4-3.9)$ & 3.63 & $3.60(3.3-3.9)$ & 3.72 & $3.62(3.4-3.8)$ & 3.66 & $t=0.13$ & 0.09 \\
\hline Not clinically significant & 670 & 74.9 & 411 & 75.1 & 1081 & 75.0 & $\chi^{2}=0.01$ & 0.02 \\
\hline Clinically significant & 225 & 25.1 & 136 & 24.9 & 361 & 25.0 & & \\
\hline Total & 895 & 100 & 547 & 100 & 1442 & 100 & & \\
\hline \multicolumn{9}{|l|}{ NIDA-ASSIST } \\
\hline Mean $(95 \% \mathrm{Cl})$ & 3.35 (3.0-3.6) & 4.54 & $4.24(3.8-4.6)$ & 4.78 & 3.69 (3.4-3.9) & 4.65 & $\boldsymbol{t}=-3.51 * * * *$ & $-3.21 * * *$ \\
\hline Low Risk & 609 & 69.0 & 324 & 59.6 & 933 & 65.4 & 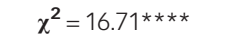 & $13.59 * * *$ \\
\hline Moderate Risk & 267 & 30.2 & 219 & 40.3 & 486 & 34.1 & & \\
\hline High Risk & 7 & 0.8 & 1 & 0.2 & 8 & 0.6 & & \\
\hline Total & 883 & 100 & 544 & 100 & 1427 & 100 & & \\
\hline \multicolumn{9}{|l|}{ SBQ-R } \\
\hline Mean $(95 \% \mathrm{Cl})$ & $5.72(5.5-5.9)$ & 3.12 & $6.08(5.8-6.4)$ & 3.68 & $5.86(5.7-6.0)$ & 3.34 & $\boldsymbol{t}=-1.89$ & -1.66 \\
\hline Not clinically significant & 608 & 68.7 & 350 & 65.1 & 958 & 67.3 & $\chi^{2}=2.02$ & 1.53 \\
\hline Clinically significant & 277 & 31.3 & 188 & 34.9 & 465 & 32.7 & & \\
\hline Total & 885 & 100 & 538 & 100 & 1423 & 100 & & \\
\hline \multicolumn{9}{|c|}{ 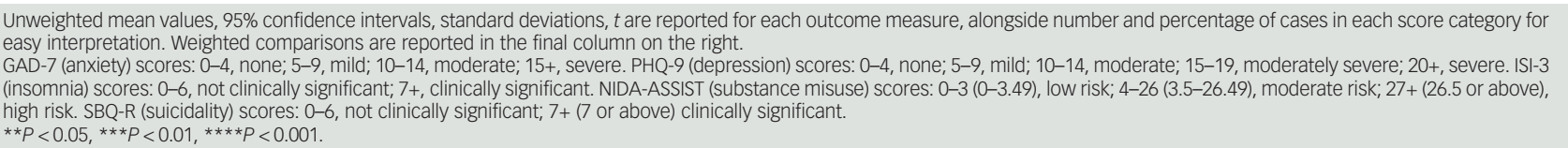 } \\
\hline
\end{tabular}

\section{Longitudinal analysis}

Participant characteristics and attrition at $\mathrm{T} 2$

Of the 365 student participants recruited from a single university who consented to being recontacted, 201 participants completed the second survey at T2 (44.9\% attrition). Table 4 presents these participants' characteristics based on available data.

\section{Changes in mental health symptoms between $\mathrm{T} 1$ and $\mathrm{T} 2$}

There was a significant reduction in reported anxiety and depression between $\mathrm{T} 1$ and $\mathrm{T} 2$, as shown in Table 5 . The percentage of participants reporting any symptoms of anxiety reduced from $72.1 \%$ at $\mathrm{T} 1$ to $59.3 \%$ at $\mathrm{T} 2$. There was little change in the percentage of participants experiencing mild and moderate anxiety symptoms, but between $\mathrm{T} 1$ and $\mathrm{T} 2$ the percentage of participants reporting severe symptoms fell from $18.4 \%$ to $6.9 \%$. Similarly, the percentage of participants reporting any depression symptoms fell from $69.8 \%$ to $61.4 \%$. For depression, there was little change in the percentage of participants experiencing severe symptoms, whereas the number of participants experiencing mild symptoms fell by $4.8 \%$ and the percentage of participants experiencing moderately severe symptoms fell by $3.2 \%$.

There were no significant differences in reported insomnia, substance misuse or suicidality between $\mathrm{T} 1$ and $\mathrm{T} 2$, even though the percentage of participants reporting clinically significant insomnia dropped from $23.2 \%$ to $16.8 \%$ and the percentage with clinically significant suicide risk rose from $35.4 \%$ to $37 \%$. There were no participants reporting high-risk substance misuse at either T1 or T2, but the percentage reporting moderate risk increased from 19.7\% to $21.2 \%$.

\section{Risk factors for mental health symptoms at $\mathrm{T} 2$}

Anxiety. The only significant risk factor for anxiety was having difficulty sleeping at $\mathrm{T} 1$. The $\mathrm{R}^{2}$ for model 2 was 0.121 (Table 6). After adjusting for baseline status (see model 3 results in Table 7), $\mathrm{T} 1$ anxiety score was the only significant risk factor. The $\mathrm{R}^{2}$ for model 3 was 0.331 .

Depression. The only significant risk factors for depression were worse financial status and difficulty sleeping at T1. The $\mathrm{R}^{2}$ for model 2 was 0.155 . In model 3, T1 depression score was the only significant risk factor. The $\mathrm{R}^{2}$ for model 3 was 0.455 .

Insomnia. The only significant risk factor for insomnia was difficulty sleeping at $\mathrm{T} 1$. The $\mathrm{R}^{2}$ for model 2 was 0.154 . In model 3, $\mathrm{T} 1$ insomnia score was the only significant risk factor. The $\mathrm{R}^{2}$ for model 3 was 0.180 .

Substance misuse. The significant risk factors for substance misuse were not being a 'morning lark' and difficulty sleeping at T1. The $\mathrm{R}^{2}$ for model 2 was 0.080 . In model $3, \mathrm{~T} 1$ substance misuse score was the only significant risk factor. The $\mathrm{R}^{2}$ for model 3 was 0.563 .

Suicidality. The significant risk factors for suicidality were reduced physical activity and worse financial status at T1. The $\mathrm{R}^{2}$ for model 2 was 0.103 . In model 3 , T1 suicidality scores and 
Table 3 Risk markers for anxiety, depression, insomnia, substance misuse and suicidality at T1, based on model 2

\begin{tabular}{|c|c|c|c|c|c|c|c|c|c|c|}
\hline \multirow[b]{2}{*}{ Variable } & \multicolumn{2}{|c|}{ Anxiety (GAD-7) } & \multicolumn{2}{|c|}{ Depression (PHQ-9) } & \multicolumn{2}{|c|}{ Insomnia (ISI-3) } & \multicolumn{2}{|c|}{$\begin{array}{c}\text { Substance misuse } \\
\text { (NIDA-ASSIST) }\end{array}$} & \multicolumn{2}{|c|}{ Suicidality (SBQ-R) } \\
\hline & $\beta$ & B & $\beta$ & B & $\beta$ & B & $\beta$ & B & $\beta$ & B \\
\hline \multicolumn{11}{|l|}{ Demographic characteristics } \\
\hline Student status & & & & & & & $-0.108^{\star \star *}$ & -1.037 & & \\
\hline Age & $-0.098^{\star \star \star \star}$ & -0.100 & $-0.100^{\star * \star *}$ & -0.107 & 0.034 & 0.021 & 0.023 & 0.018 & $-0.138^{\star * * *}$ & -0.078 \\
\hline Gender: female & 0.046 & 0.560 & 0.003 & 0.044 & 0.000 & 0.002 & $-0.106^{\star * * *}$ & -0.997 & & \\
\hline Gender: male & & & & & & & & & 0.045 & 0.305 \\
\hline Gender: other & & & & & & & & & $0.057^{\star *}$ & 1.535 \\
\hline White/Caucasian & & & & & & & -0.005 & -0.053 & & \\
\hline \multicolumn{11}{|l|}{ Black/Black British } \\
\hline Asian/Asian British & & & & & 0.029 & 0.318 & $-0.084^{\star \star}$ & -1.185 & & \\
\hline Mixed ethnicity & & & & & $0.035^{*}$ & 0.548 & & & & \\
\hline Currently UK-based & & & & & & & $-0.146^{\star * \star *}$ & -1.596 & & \\
\hline $\begin{array}{l}\text { Changed location (past } 3 \\
\text { months) }\end{array}$ & & & & & & & & & 0.048 & 0.389 \\
\hline Living with: family & & & & & & & -0.045 & -0.539 & & \\
\hline $\begin{array}{l}\text { Living with: friends/ } \\
\text { housemates }\end{array}$ & & & & & & & $0.076^{* *}$ & 1.270 & & \\
\hline \multicolumn{11}{|l|}{ Living with: partner } \\
\hline \multirow{2}{*}{\multicolumn{11}{|c|}{$\begin{array}{l}\text { Living with: other } \\
\text { Living alone }\end{array}$}} \\
\hline & & & & & & & & & & \\
\hline \multirow{2}{*}{\multicolumn{11}{|c|}{$\begin{array}{l}\text { Living with } 1-2 \text { others } \\
\text { Living with } 3+\text { other }\end{array}$}} \\
\hline & & & & & & & & & & \\
\hline Physical health condition & -0.010 & -0.158 & -0.008 & -0.125 & -0.035 & -0.330 & & & 0.019 & 0.165 \\
\hline Mental health condition & $0.238^{\star \star \star \star}$ & 3.185 & $0.254^{\star \star \star \star}$ & 3.587 & $0.071^{\star \star \star *}$ & 0.578 & $0.170^{* * * *}$ & 1.755 & $0.436^{\star * \star *}$ & 3.238 \\
\hline Using health app & 0.025 & 0.314 & & & $0.054^{\star \star *}$ & 0.408 & & & & \\
\hline Carer & $0.082^{\star \star \star}$ & 1.546 & $0.096^{* * * *}$ & 1.909 & $0.037^{\star \star *}$ & 0.424 & & & & \\
\hline Chronotype: morning lark & & & -0.015 & -0.231 & -0.035 & -0.301 & & & & \\
\hline Chronotype: night owl & & & 0.026 & 0.327 & -0.001 & -0.010 & & & 0.020 & 0.134 \\
\hline$\Delta R^{2}$ & 0.120 & & 0.130 & & 0.093 & & 0.087 & & 0.229 & \\
\hline$\Delta F$ & $26.699 * * * *$ & & $25.108^{* * * *}$ & & $11.373^{* * * *}$ & & $11.554^{* * * *}$ & & $49.245^{* * * *}$ & \\
\hline \multicolumn{11}{|l|}{ COVID-19 risk and exposure } \\
\hline COVID high risk & 0.022 & 0.725 & 0.028 & 0.981 & 0.017 & 0.334 & 0.035 & 0.899 & 0.006 & 0.115 \\
\hline COVID moderate risk & 0.021 & 0.372 & 0.022 & 0.410 & 0.026 & 0.283 & & & 0.010 & 0.094 \\
\hline Tested positive & & & & & & & $0.072^{\star \star}$ & 3.214 & & \\
\hline $\begin{array}{l}\text { Tested positive - close } \\
\text { family }\end{array}$ & 0.018 & 0.340 & 0.022 & 0.428 & 0.005 & 0.059 & & & & \\
\hline $\begin{array}{l}\text { Tested positive - extended } \\
\text { network }\end{array}$ & 0.045 & 0.591 & 0.024 & 0.336 & 0.032 & 0.251 & & & & \\
\hline$\Delta R^{2}$ & 0.010 & & 0.010 & & 0.106 & & 0.007 & & 0.001 & \\
\hline$\Delta F$ & $3.480^{* * *}$ & & $3.447^{* * *}$ & & $4.107^{* * *}$ & & $4.122^{\star *}$ & & 0.654 & \\
\hline \multicolumn{11}{|l|}{ Changes since lockdown } \\
\hline Work hours & -0.036 & -0.363 & -0.032 & -0.335 & -0.009 & -0.056 & -0.051 & -0.392 & -0.047 & -0.263 \\
\hline $\begin{array}{l}\text { Physical activity } \\
\text { News consumption }\end{array}$ & -0.018 & -0.123 & $-0.078^{\star \star *}$ & -0.554 & -0.012 & -0.049 & & & & \\
\hline \multicolumn{11}{|l|}{$\begin{array}{l}\text { Social media use } \\
\text { (socialising) }\end{array}$} \\
\hline Financial status & $-0.136^{\star * \star *}$ & -1.076 & $-0.133^{\star \star \star \star}$ & -1.118 & -0.020 & -0.094 & $-0.073^{\star \star}$ & -0.447 & $-0.061^{\star *}$ & -0.267 \\
\hline Sleep duration & & & -0.004 & -0.027 & & & & & & \\
\hline Sleep quality & -0.019 & -0.167 & -0.033 & -0.301 & -0.022 & -0.117 & & & & \\
\hline Sleeping earlier & & & 0.014 & 0.328 & 0.010 & 0.132 & & & 0.013 & 0.103 \\
\hline Sleeping later & & & & & 0.004 & 0.029 & & & & \\
\hline Sleep pattern more irregular & $0.109^{\star * * *}$ & 1.537 & $0.117^{\star * \star *}$ & 1.751 & $0.047^{\star \star}$ & 0.406 & $0.077^{\star \star *}$ & 0.846 & & \\
\hline $\begin{array}{l}\text { Difficulty sleeping } \\
\text { New friends }\end{array}$ & $0.299 * * \star \star$ & 3.642 & $0.319^{\star \star \star \star}$ & 4.105 & $0.767^{* * * *}$ & 5.668 & 0.039 & 0.363 & $0.147^{\star \star \star \star}$ & 0.994 \\
\hline $\begin{array}{l}\text { New hobbies } \\
\text { New voluntary work }\end{array}$ & 0.028 & 0.339 & & & & & & & & \\
\hline Acts of kindness & & & & & 0.006 & 0.046 & & & & \\
\hline$\Delta R^{2}$ & 0.150 & & 0.173 & & 0.567 & & 0.020 & & 0.030 & \\
\hline$\Delta F$ & $30.243^{* * * *}$ & & $32.552^{* * * *}$ & & $190.296^{* * * *}$ & & $6.095^{\star * * *}$ & & $11.853^{* * * *}$ & \\
\hline Full model - $\mathbf{R}^{2}$ & 0.280 & & 0.314 & & 0.673 & & 0.114 & & 0.260 & \\
\hline Full model - F & $25.135^{\star * * *}$ & & $26.519 * * * *$ & & $94.144^{* * * *}$ & & $9.288 * * * *$ & & $31.245^{* * * *}$ & \\
\hline $\begin{array}{l}\text { Model } 2 \text { is a multivariate hierarchica } \\
\text { characteristics' } \rightarrow \text { 'COVID-19 risk and } \\
\text { ('hange) and } \Delta \text { (change) are presen } \\
\text { Empty boxes exist because only sign } \\
\text { female), except several of the 'chan } \\
\text { decrease/worse off. Multicollinearity } \\
\text { model stability and accuracy (anxiet) } \\
\text { gender: male. } \\
\beta \text {, standardised beta coefficient; B, } \\
{ }^{*} P=0.05 \text {, }{ }^{* *} P<0.05 \text {, }{ }^{* * * P} P 0.01 \text {, * }\end{array}$ & $\begin{array}{l}\text { linear regression r } \\
\text { exposure' } \rightarrow \text { 'Cha } \\
\text { ed for each block } \\
\text { ficant predicting ve } \\
\text { es since lockdown } \\
\text { as indicated by vo } \\
\text { model, gender: } m \\
\text { nstandardised betc } \\
\star \star P<0.001 \text {. }\end{array}$ & $\begin{array}{l}\text { model, wher } \\
\text { nges since l } \\
\text { of predictors } \\
\text { ariables in m } \\
\text { 'variables (f } \\
\text { raiance inflat } \\
\text { ale; depress } \\
\text { coefficient. }\end{array}$ & $\begin{array}{l}\text { ein all significant } \\
\text { ockdown'). Result } \\
R^{2} \text { and } F \text { are pre } \\
\text { odel } 1 \text { were incluo } \\
\text { rom work hours t } \\
\text { ion factor (VIF) }>4 \\
\text { ion model, gende }\end{array}$ & $\begin{array}{l}\text { univariate pr } \\
\text { s from the w } \\
\text { sented for th } \\
\text { ded in model } \\
\text { to financial } s \\
\text { 4, was detec } \\
\text { r: male; inso }\end{array}$ & $\begin{array}{l}\text { redictors from moc } \\
\text { veighted analysis a } \\
\text { he full model. A full } \\
\text { I. All categorical } \\
\text { tatus), which were } \\
\text { ted between predi }\end{array}$ & $\begin{array}{l}\text { lel } 1(P<0.0 \\
\text { e presented } \\
\text { list of predi } \\
\text { ariables we } \\
\text { coded as } 1 \\
\text { ctors within } \\
\text { er: male and }\end{array}$ & $\begin{array}{l}\text { ) were included a } \\
\text { to show patterns } \\
\text { ting variables is p } \\
\text { e dummy coded, } \\
\text { = increase/better } \\
\text { models. Individua } \\
\text { ethnicity: White/ }\end{array}$ & $\begin{array}{l}\text { ind entered } \\
\text { of significan } \\
\text { resented in } \\
\text { e.g. gender: } \\
\text { off } 0=\text { = stay } \\
\text { I predictors } \\
\text { Caucasian; }\end{array}$ & $\begin{array}{l}\text { by block ('Demog } \\
\text { ce (highlighted in } \\
\text { the first column o } \\
\text { female }(1,=\text { femal } \\
\text { ed about the same } \\
\text { were removed to } \\
\text { ubstance misuse }\end{array}$ & $\begin{array}{l}\text { aphic } \\
\text { oold). } \Delta R^{2} \\
\text { n the left. } \\
e, 0=\text { not } \\
-1= \\
\text { maintain } \\
\text { model, }\end{array}$ \\
\hline
\end{tabular}




\section{Table 4 Participant characteristics at T2}

Variable

Age (years)

20 or under

21-24

25-29

30 or over

Total

Gender

Female

Male

Other

Total

Ethnicity

White/Caucasian

African/Caribbean/ Black British

Asian/Asian British

Mixed

Other

Total

Current location

UK

Non-UK

Total

Current household members

Family

Friend/housemates

Partners

Other

Total ${ }^{2}$

Current household size

Alone

1-2 other people

$3+$ other people

Other

Total

Physical health condition ${ }^{\mathrm{b}}$

Yes

No

Other

Total

Mental health condition ${ }^{b}$

Yes

No

Other

Total

Using a health tracker app

Yes

No

Other

Total

Carer status

Yes

No

Other

Total

Sleep chronotype

Morning lark

Night owl

Other

Total

COVID-19 high risk

Yes

No

Other

Total

COVID-19 moderate risk ${ }^{\mathrm{d}}$

Yes

No

Other
Students

Mean, $n \quad$ s.d., \%

23.85

8.15

81

30

190

129

3

191

132

6

38

11

190

162

28

190

139

18

12

7

176

14

77

99

0

190

46

142

2

190

53

131

6

190

72

118

0

190

15

173

190

53

83

54

190

3

187

190

26

163
Table 4 (Continued)

\begin{tabular}{|c|c|c|}
\hline \multirow[b]{2}{*}{ Variable } & \multicolumn{2}{|c|}{ Students } \\
\hline & Mean, $n$ & s.d., \% \\
\hline Total & 190 & 100 \\
\hline \multicolumn{3}{|c|}{ Tested positive for COVID-19 } \\
\hline Yes & 1 & 0.5 \\
\hline No & 188 & 98.9 \\
\hline Other & 1 & 0.5 \\
\hline Total & 190 & 100 \\
\hline \multicolumn{3}{|c|}{ Tested positive for COVID-19 (family/friends) } \\
\hline Yes & 15 & 7.9 \\
\hline No & 175 & 92.1 \\
\hline Other & 0 & 0 \\
\hline Total & 190 & 100 \\
\hline \multicolumn{3}{|c|}{ Tested positive for COVID-19 (extended family/social network) } \\
\hline Yes & 86 & 45.0 \\
\hline No & 104 & 54.5 \\
\hline Other & 0 & 0 \\
\hline Total & 190 & 100 \\
\hline
\end{tabular}

Additional student characteristics

Student type

Home/UK

EU

International

Visiting student

Other

Total

Study level

Undergraduate

Postgraduate

Other

Total

Course type

Full-time

Part-time

Other

Total

$140 \quad 73.7$

25

0

0

190

0
0

100

Exams this academic year

Yes

No

Other

Total

123

64

0

187

169

21

0

190

65.8

4.2

0

100

88.9

11.1

0

100

\begin{tabular}{l}
$76 \quad 40.9$ \\
\hline
\end{tabular}

$49 \quad 26.3$

$61-328$

Unweighted frequency and percentage are reported for all variables except age, for which mean, standard deviation and $t$ are reported also.

a. Excluding those who answered 'living alone' in the current household size question. b. Physical health problem and mental health problem refer specifically to diagnosed conditions.

c. High risk: as defined by UK government regulations - received bone marrow or stem cell transplant in the past 6 months, or are still taking immunosuppressant medicine received an organ transplant, severe lung condition (such as cystic fibrosis, severe

asthma or severe chronic obstructive pulmonary disease (COPD)), having chemotherapy

or antibody treatment for cancer, including immunotherapy, have a condition that

means a very high risk of getting infections (such as SCID or sickle cell), having an intense

course of radiotherapy (radical radiotherapy) for lung cancer, taking medicine that

course of radiotherapy (radical radiotherapy) for lung cancer, taking medicine that
makes them much more likely to get infections (such as high doses of steroids), having

targeted cancer treatments that can affect the immune system (such as protein kinase targeted cancer treatments that can affect the immune system (such as protein kinase
inhibitors or PARP inhibitors), have a serious heart condition and are pregnant, had blood inhibitors or PARP inhibitors), have a serious heart condition and are preg
or bone marrow cancer (such as leukaemia, lymphoma or myeloma).

d. Moderate risk: as defined by UK government regulations - have liver disease (such as

hepatitis), aged 70 or older, have a condition affecting the brain or nerves (such as

Parkinson's disease, motor neurone disease, multiple sclerosis or cerebral palsy),

pregnant, have a condition that means a high risk of getting infections, have a lung

condition that is not severe (such as asthma, COPD, emphysema or bronchitis), taking

medicine that can affect the immune system (such as low doses of steroids), have heart

disease (such as heart failure), very obese (body mass index of 40 or above), have dia-

betes, have chronic kidney disease.

e. Undergraduate included bachelor's and foundation students.

reduced physical activity were significant risk factors. The $\mathrm{R}^{2}$ for model 3 was 0.665 .

\section{Discussion}

\section{Main findings}

University students and young adults reported high levels of mental health problems even after the first lockdown in the UK as they 
Table 5 Mental health symptoms of follow-up responders and comparisons between T1 and T2

\begin{tabular}{|c|c|c|c|c|c|c|}
\hline \multirow[b]{2}{*}{ variable $^{a}$} & \multicolumn{2}{|c|}{ T1 } & \multicolumn{2}{|c|}{ T2 } & \multirow{2}{*}{$\begin{array}{c}\text { Comparison } \\
t \text { mean difference }(95 \% \mathrm{Cl})\end{array}$} & \multirow{2}{*}{$\begin{array}{c}\text { Weighted comparison } \\
t \text { mean difference }(95 \% \mathrm{Cl})\end{array}$} \\
\hline & Mean, $n$ & s.d., \% & Mean, $n$ & s.d., \% & & \\
\hline \multicolumn{7}{|l|}{ GAD-7 } \\
\hline Mean & 8.65 & 5.93 & 6.68 & 5.04 & $5.14^{\star * * *} 1.97(1.22-2.73)$ & $4.76^{\star * * *} 1.91(1.12-2.71)$ \\
\hline None & 53 & 27.9 & 77 & 40.7 & & \\
\hline Mild & 55 & 28.9 & 56 & 29.6 & & \\
\hline Moderate & 47 & 24.7 & 43 & 22.8 & & \\
\hline Severe & 35 & 18.4 & 13 & 6.9 & & \\
\hline Total & 190 & 100 & 189 & 100 & & \\
\hline \multicolumn{7}{|l|}{ PHQ-9 } \\
\hline Mean & 8.18 & 5.70 & 7.45 & 5.92 & $2.08^{\star *}, 0.73(0.04-1.42)$ & $1.98^{\star}, 0.73(0.00-1.47)$ \\
\hline None & 57 & 30.2 & 73 & 38.6 & & \\
\hline Mild & 68 & 36.0 & 59 & 31.2 & & \\
\hline Moderate & 28 & 14.8 & 27 & 14.3 & & \\
\hline Moderately Severe & 26 & 13.8 & 20 & 10.6 & & \\
\hline Severe & 10 & 5.3 & 10 & 5.3 & & \\
\hline Total & 189 & 100 & 189 & 100 & & \\
\hline \multicolumn{7}{|l|}{$|S|-3$} \\
\hline Mean & 3.64 & 3.45 & 3.11 & 3.31 & $1.86,0.53(-0.03-1.10)$ & $1.50,0.45(-0.15-1.05)$ \\
\hline Not clinically significant & 146 & 76.8 & 158 & 83.2 & & \\
\hline Clinically significant & 44 & 23.2 & 32 & 16.8 & & \\
\hline Total & 190 & 100 & 190 & 100 & & \\
\hline \multicolumn{7}{|l|}{ NIDA-ASSIST } \\
\hline Mean & 2.18 & 2.71 & 2.29 & 3.03 & $-0.70,-0.11(-0.41-0.20)$ & $-0.67,-0.11(-0.43-0.21)$ \\
\hline Low Risk & 151 & 80.3 & 149 & 78.8 & & \\
\hline Moderate Risk & 37 & 19.7 & 40 & 21.2 & & \\
\hline High Risk & 0 & 0 & 0 & 0 & & \\
\hline Total & 188 & 100 & 189 & 100 & & \\
\hline \multicolumn{7}{|l|}{ SBQ-R } \\
\hline Mean & 5.92 & 2.91 & 6.03 & 3.34 & $-0.77,-0.11(-0.40-0.17)$ & $-0.71,-0.11(-0.41-0.19)$ \\
\hline Not clinically significant & 122 & 64.6 & 119 & 63.0 & & \\
\hline Clinically significant & 67 & 35.4 & 70 & 37.0 & & \\
\hline Total & 189 & 100 & 189 & 100 & & \\
\hline \multicolumn{7}{|c|}{ 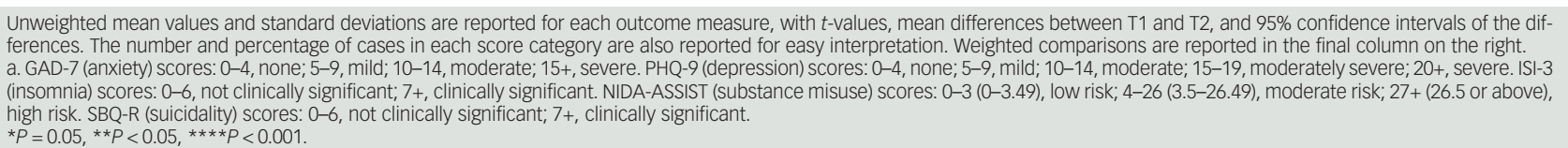 } \\
\hline
\end{tabular}

resumed some form of 'normality'. More than a third reported moderate to severe symptoms of anxiety and depression and risk of substance misuse. Over a quarter reported experiencing insomnia and clinically significant suicidal thoughts and behaviour. These rates approximated those reported by a previous US study ${ }^{2}$ but were higher than those reported in other large-scale studies conducted in China, France and the UK during the early stage of the pandemic. ${ }^{1,3,5}$ In contrast to the Italian finding that levels of depression rapidly returned to pre-pandemic levels once restrictions were lifted, ${ }^{11}$ the $\mathrm{T} 1$ data of this study suggested that the lockdown had a sustained impact on mental health beyond the duration of the restrictions. That said, we acknowledge that mental health problems in student cohorts have been an issue prior to the pandemic. The lockdown should not be considered to be the sole contributor to the high prevalence.

When a subset of university students was reassessed 6 months later - just as the UK entered the third lockdown - we saw significant reductions in symptoms of anxiety and depression. These changes suggest possible emotional adaptations as the situation evolved. ${ }^{26}$ However, some mental health issues appeared to be more ingrained than others; we did not see significant reductions in insomnia, substance misuse or suicidal risk, with $16.8 \%$ still presenting with clinically significant insomnia, $21.2 \%$ with moderate risk of substance misuse and $37 \%$ with clinically significant suicide risk at T2. The differential trajectories of different mental health symptoms suggest that university well-being services may benefit from a stronger focus on addressing irregularities in sleepwake patterns, risky behaviours and suicide prevention as young people navigate through cycles of lockdown and lifting of restrictions.

Overall, despite differences in demographics and changes in behaviours and circumstances, university students and their broadly age-matched counterparts in this study were remarkably similar in their reported levels of mental health symptoms. Much of the risk associated with mood and sleep regulation and with suicidality during the pandemic was shared among young people regardless of their student status, suggesting an opportunity to cross-fertilise lessons learned across university and non-university settings for the development of better prevention and treatment strategies.

However, risk factors identified for each of the five mental health symptoms examined varied depending on the analytical approach used. In our cross-sectional models at T1, COVID risk and exposure were not the most significant risk markers of mental health symptoms. Instead, demographic characteristics and behavioural and circumstantial changes during lockdown were more significant and consistent risk markers across outcome measures. The most consistent of all were younger age, pre-existing mental health condition(s), being a carer, worse financial status, having a more irregular sleep pattern and increased difficulty sleeping. The total amounts of variance explained by our cross-sectional models using $\mathrm{T} 1$ data were $28 \%$ for anxiety, $31 \%$ for depression, $67 \%$ for insomnia, $11 \%$ for substance misuse and $26 \%$ for suicidality. In our longitudinal models using data from a more homogenous subgroup of university students with a 6-month time gap between predictors and outcomes, the total amounts of variance explained were 
Table 6 Risk factors for anxiety, depression, insomnia, substance misuse and suicidality at T2, based on model 2

\begin{tabular}{|c|c|c|c|c|c|c|c|c|c|c|}
\hline \multirow[b]{2}{*}{ Variable } & \multicolumn{2}{|c|}{ Anxiety (GAD-7) } & \multicolumn{2}{|c|}{ Depression (PHQ-9) } & \multicolumn{2}{|c|}{ Insomnia (ISI-3) } & \multicolumn{2}{|c|}{$\begin{array}{c}\text { Substance misuse } \\
\text { (NIDA-ASSIST) }\end{array}$} & \multicolumn{2}{|c|}{ Suicidality (SBQ-R) } \\
\hline & $\beta$ & B & $\beta$ & B & $\beta$ & B & $\beta$ & B & $\beta$ & B \\
\hline \multirow{2}{*}{\multicolumn{11}{|c|}{ Demographic characteristics }} \\
\hline & \multicolumn{10}{|c|}{$\begin{array}{l}\text { Age } \\
\text { Gender: female }\end{array}$} \\
\hline \multicolumn{11}{|l|}{ Gender: female } \\
\hline \\
\hline & & & & & & & & & & \\
\hline \multicolumn{11}{|l|}{$\begin{array}{l}\text { Gender. Otner } \\
\text { White/Caucasian }\end{array}$} \\
\hline Black/Black British & & & & & & & & & & \\
\hline Asian/Asian British & & & & & & & & & & \\
\hline Mixed ethnicity & & & & & & & & & & \\
\hline Currently UK-based & & & & & & & & & & \\
\hline Changed location (past 3 months) & & & & & & & & & & \\
\hline Living with: family & & & & & & & & & & \\
\hline Living with: friends/housemates & & & & & & & & & & \\
\hline Living with: partner & & & & & & & & & & \\
\hline Living with: other & & & & & & & & & & \\
\hline Living alone & & & & & & & & & & \\
\hline Living with 1-2 others & & & & & & & & & & \\
\hline Living with 3+ other & & & & & & & & & & \\
\hline Physical health condition & & & & & & & & & & \\
\hline Mental health condition & & & & & & & & & & \\
\hline Using health app & & & & & & & & & & \\
\hline Carer & & & & & & & & & & \\
\hline Chronotype: morning lark & & & & & & & $-0.180^{\star *}$ & -1.230 & & \\
\hline Chronotype: night owl & & & & & & & & & & \\
\hline$\Delta R^{2}$ & & & & & & & 0.040 & & & \\
\hline$\Delta F$ & & & & & & & $6.721^{*}$ & & & \\
\hline Student characteristics & & & & & & & & & & \\
\hline Home student or not & & & & & & & & & & \\
\hline UG or PG & & & & & & & & & & \\
\hline FT or PT & & & & & & & & & & \\
\hline Exams this year & & & & & & & & & & \\
\hline$\Delta R^{2}$ & & & & & & & & & & \\
\hline$\Delta F$ & & & & & & & & & & \\
\hline COVID-19 risk and exposure & & & & & & & & & & \\
\hline COVID high risk & & & 0.131 & 6.597 & & & & & & \\
\hline COVID moderate risk & & & & & & & & & & \\
\hline Tested positive & & & & & & & & & & \\
\hline Tested positive - close family & & & & & & & & & & \\
\hline Tested positive - extended network & & & & & 0.129 & 0.850 & & & & \\
\hline$\Delta R^{2}$ & & & 0.0 & & 0.02 & & & & & \\
\hline$\Delta F$ & & & 4.20 & & 4.013 & & & & & \\
\hline Changes since lockdown & & & & & & & & & & \\
\hline Study hours & -0.128 & -0.793 & -0.128 & -0.932 & -0.122 & -0.499 & & & & \\
\hline $\begin{array}{l}\text { Study engagement } \\
\text { Work hours }\end{array}$ & -0.040 & -0.274 & -0.087 & -0.698 & & & & & & \\
\hline Physical activity & & & & & & & & & $-0.176^{\star *}$ & -0.661 \\
\hline News consumption & & & & & & & & & & \\
\hline $\begin{array}{l}\text { Social media use (general browsing) } \\
\text { social media use (socialising) }\end{array}$ & 0.077 & 0.680 & & & & & & & 0.129 & 0.759 \\
\hline Financial status & -0.109 & -0.668 & $-0.152^{\star *}$ & -1.125 & -0.123 & -0.514 & & & $-0.156^{\star *}$ & -0.663 \\
\hline Sleep duration & & & & & & & & & & \\
\hline Sleep quality & & & & & & & & & & \\
\hline Sleeping earlier & & & & & & & & & & \\
\hline Sleeping later & & & & & & & & & & \\
\hline Sleep pattern more irregular & 0.095 & 1.175 & 0.045 & 0.655 & 0.060 & 0.483 & & & & \\
\hline Difficulty sleeping & $0.173^{\star *}$ & 1.779 & $0.205^{\star * *}$ & 2.462 & $0.266^{\star * *}$ & 1.796 & $0.201^{\star * *}$ & 1.260 & 0.104 & 0.715 \\
\hline New friends & & & & & & & & & & \\
\hline New hobbies & & & & & & & & & & \\
\hline New voluntary work & & & & & & & & & & \\
\hline Acts of kindness & & & & & & & & & & \\
\hline$\Delta R^{2}$ & 0.12 & & 0.1 & & 0.12 & & 0.040 & & $0.1 c$ & \\
\hline$\Delta F$ & 3.556 & & 4.766 & & $6.011^{\star}$ & & $6.915^{\star \star}$ & & 4.536 & \\
\hline Full model - $\mathbf{R}^{2}$ & 0.12 & & 0.1 & & 0.15 & & 0.080 & & $0.1 c$ & \\
\hline Full model - F & 3.556 & & 4.756 & & $5.711^{\star}$ & **** & $6.942^{\star \star}$ & & 4.536 & *** \\
\hline $\begin{array}{l}\text { Model } 2 \text { is a multivariate hierarchical linear reg } \\
\text { characteristics' } \rightarrow \text { 'Student characteristics' } \rightarrow \\
\text { cance (highlighted in bold). } \Delta R^{2} \text { (change) and } \Delta F \\
\text { the first column on the left. Empty boxes exist } \\
\text { coefficient; } \mathrm{FT} \text {, full-time; } \mathrm{PG} \text {, postgraduate; } \mathrm{PT} \text {, }\end{array}$ & $\begin{array}{l}\text { ession model, } \\
\text { covID-19 risk a } \\
\text { (change) are pre } \\
\text { ecause only si } \\
\text { Dart-time; UG, } 4\end{array}$ & $\begin{array}{l}\text { wherein all } \\
\text { nd exposure } \\
\text { esented for } \\
\text { gnificant pre } \\
\text { undergradua }\end{array}$ & $\begin{array}{l}\text { ignificant unive } \\
\rightarrow \text { 'Changes } \\
\text { ach block of pr } \\
\text { dicting variable } \\
\text { te. }\end{array}$ & $\begin{array}{l}\text { late predictc } \\
\text { coe lockdow } \\
\text { dictors. } R^{2} \text { ar } \\
\text { in model } 1 \mathrm{v}\end{array}$ & $\begin{array}{l}\text { rs from model } 1 \\
\left.n^{\prime}\right) \text {. Results from } \\
\text { dd } F \text { are presente } \\
\text { vere included in }\end{array}$ & $\begin{array}{l}\text { I }(P<0.05) \mathrm{W} \\
\text { the weight } \\
\text { ed for the ful } \\
\text { model 2. } \beta \text {, }\end{array}$ & $\begin{array}{l}\text { re included and } \\
\text { d analysis are pre } \\
\text { model. A full list of } \\
\text { tandardised beta }\end{array}$ & $\begin{array}{l}\text { entered by } \\
\text { esented to } \\
\text { of predictin } \\
\text { coefficien }\end{array}$ & $\begin{array}{l}\text { block ('Demog } \\
\text { show patterns } \\
\text { variables is pre } \\
\text {; B, unstandarc }\end{array}$ & $\begin{array}{l}\text { aphic } \\
\text { of signifi- } \\
\text { sented in } \\
\text { ised beta }\end{array}$ \\
\hline
\end{tabular}


Table 7 Risk factors for anxiety, depression, insomnia, substance misuse and suicidality at T2, based on model 3

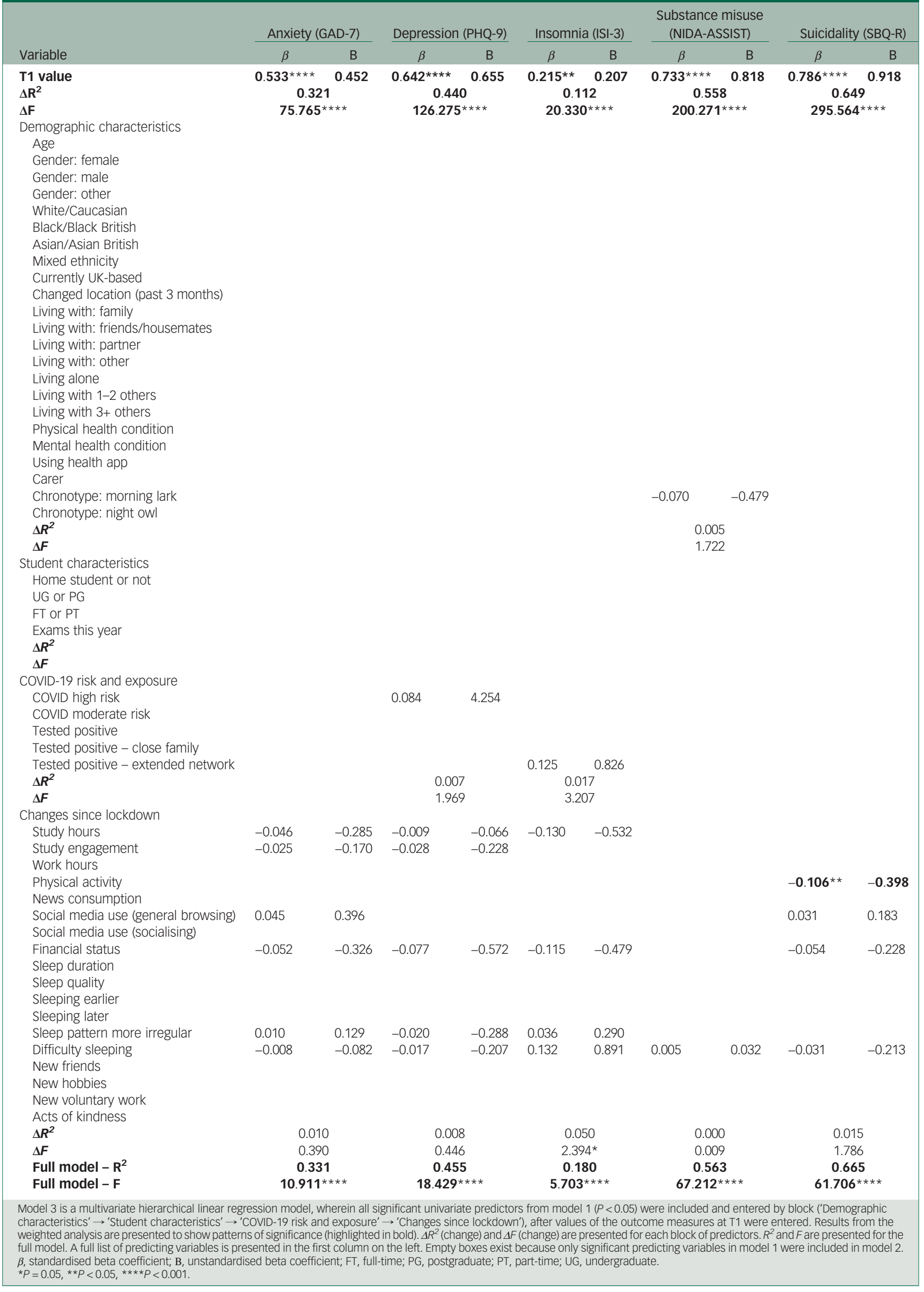


reduced to $12 \%, 16 \%, 15 \%, 8 \%$ and $10 \%$ for the respective outcome measures of interest. In these longitudinal models, the range of significant predictors reduced, and the most consistent predictors of mental health symptoms at T2 were worse financial status and having difficulty sleeping since lockdown. These findings add to the existing literature on the mental health risk associated with financial pressure. ${ }^{27,28}$ They are also consistent with the view that circadian misalignment and sleep difficulties were common consequences of the pandemic that negatively affected core aspects of well-being and contributed to the aggravation of pre-existing psychological problems. ${ }^{29}$

The amount of variance explained rebounded and increased to $33 \%$ for anxiety, $46 \%$ for depression, $18 \%$ for insomnia, $56 \%$ for substance misuse and $67 \%$ for suicidality when the regression models included baseline values of the outcome measures of interest among the predictors. Such jumps in explanatory power suggest a history effect, with previous symptoms being the strongest predictor of future symptoms. The change in $R^{2}$ for models with baseline measures only ranged from $11-65 \%$. This history effect reflects the inherent nature of mental health states, which tend to unfold over time, evolving and changing over the lifespan. ${ }^{30}$ It also underlines the importance of identifying modifiable risk factors for effective prevention and early intervention. ${ }^{31}$ In this study, we found that worse financial status and difficulty sleeping prospectively predicted more than one mental health symptom - and, having adjusted for baseline mental health states, reduced physical activity remained a significant risk predictor of greater suicidality. These findings are consistent with those of other studies with more representative adult samples ${ }^{32}$ and suggest that, in addition to providing enhanced support to vulnerable subgroups, greater efforts in maintaining promoting physical activity and ensuring financial stability throughout a generally difficult time could help to mitigate mental health risks.

\section{Strengths and limitations}

Currently, there is little published information on mental health symptoms after the initial wave of lockdown in January to March 2020. This cross-sectional and longitudinal study extends our understanding by examining the continuous impact of the pandemic on the mental health of university students and identifying the risk markers and predictors of mental health symptoms. We included a non-student comparison group to assess the generalisability of risks from young people at university to those not in higher education. We used validated measures to assess a range of reported mental health symptoms: anxiety, depression, insomnia, substance misuse and suicidality. This allowed us to establish a mental health profile, identify common risk factors and note any differential effects of the pandemic on individual symptoms over time.

Like other studies carried out under COVID restrictions, this study was an online survey and had several methodological limitations. First, our participants were recruited through both convenience sampling methods and a research participant platform to achieve the needed sample size for our planned analyses. We restricted our participant recruitment to students attending UK universities and young adults living in the UK; however, responses received included some from visiting students who were in the UK on study abroad and from overseas students studying in the UK who had returned to their home countries at the time of the study. These responses, although they reflect the international nature of the university setting, may have introduced variations in responses owing to differences in conditions and public health measures adopted in different countries. Further, self-selection biases were possible in that young people with greater interest in mental health were more likely to take part in the survey, although the demographic profile of our participants approximated that of the whole UK university student cohort (Supplementary Table 1) and the prevalence rates of mental health symptoms reported in the current study were comparable with those of published studies with larger and more representative samples. ${ }^{1-3}$

Second, for the longitudinal analysis, we followed up only a subset of university students who gave us permission to do so. Attrition at 6 months was 44\%, with 201 participants providing $\mathrm{T} 1$ and $\mathrm{T} 2$ data for the longitudinal analysis, despite incentives. The T2 sample was also ethnically less diverse than T1. It is unclear whether 'survey fatigue' and the stress associated with the emerging situation were determining factors. ${ }^{33}$ Poor response rates and high attrition seem characteristic of online surveys conducted during the pandemic, particularly among students: the Office for National Statistics conducted a survey in collaboration with the National Students Union in November 2020 and received a $2 \%$ response rate. ${ }^{34}$ Given the small sample size and the high attrition rate, the findings of the current study should be interpreted with caution even though the weighted and unweighted analyses resulted in similar patterns of findings.

Third, all measures of outcomes and risk factors were selfreported. Although validated measures were used, the responses received were subject to possible memory and reporting biases. With established cut-off scores, the scores on our outcome measures could be interpreted for potential clinical significance; however, they are no replacement for clinical diagnosis.

Finally, the current study only included two waves of data collection. To truly capture the continued impact of the pandemic on young people's mental health, more resources are required to invest in longitudinal studies with more assessments and longer follow-up periods.

\section{Implications}

A considerable proportion of university students and young adults not in higher education experienced mental health symptoms following the first UK lockdown. Although there was a reduction in reported symptoms between summer 2020 and winter 2021, rates of mental health symptoms remained elevated. The current study highlights markers for identifying those with more severe mental health symptoms and risk factors for predicting poorer mental health.

The significance of behavioural and circumstantial risk factors should prompt universities to consider a more proactive approach in mitigating financial pressures and in promoting positive health behaviours (e.g. physical activity, sleep) that can help counteract poor mental health. Similarities between risk factors for students and young people not in higher education indicate that intervention and prevention measures available for each group may be evaluated and applied to both populations for greater generalisability.

Nicole K. Y. Tang (D), Department of Psychology, University of Warwick, UK; Katharine A. M. McEnery, Department of Psychology, University of Warwick, UK; Laura Chandler, Warwick Manufacturing Group, University of Warwick, UK; Carla Toro, Warwick

Manufacturing Group, University of Warwick, UK; Lukasz Walasek, Department of

Psychology, University of Warwick, UK; Hannah Friend, Wellbeing and Safeguarding Group, Professional Services, University of Warwick, UK; Sai Gu, Executive Office and School of Engineering, University of Warwick, UK; Swaran P. Singh (D), Division of Mental Health and Wellbeing, Warwick Medical School, UK; Caroline Meyer, Warwick Manufacturing Group, University of Warwick, UK

Correspondence: Nicole K. Y. Tang. Email: n.tang@warwick.ac.uk

First received 24 Sep 2021, final revision 24 May 2022, accepted 26 May 2022

\section{Supplementary material}

Supplementary material is available online at https://doi.org/10.1192/bjo.2022.523. 


\section{Data availability}

The data that support the findings of this study are available on request from the corresponding author, N.K.Y.T. The data are not publicly available owing to ethical restrictions e.g. their containing information that could compromise the privacy of research participants.

\section{Acknowledgements}

The authors thank all participants for their time and participation at a generally difficult time. We are grateful to Lia Lovećka, Jenna Gillett, Kristy Themelis, Piotr Bogdanski and Nicole Zhang for their assistance with the implementation of the project, and to Dr Chen Ji for his statistical advice. We thank the Warwick Students' Union, Warwick Chinese Society and Chinese Students and Scholars Association for their support of the project.

\section{Author contributions}

N.K.Y.T., C.T., L.W., H.F., S.G. and C.M. were investigators of the projects. K.M., L.C., N.K.Y.T., C.T and LW led in formulating the research questions, designing and implementing the study, analysing the data and writing the article, with input from other authors. All authors were involved in the drafting, reviewing and finalising of the manuscript.

\section{Funding}

SPS is part-funded by the National Institute for Health Research (NHHR) Applied Research Collaboration West Midlands. The views expressed are those of the author(s) and not necessarCollaboration West Midlands. The views expressed are those of the author(s) and not necessar-
ily those of the NIHR or the Department of Health and Social Care. The Warwick RECOVERS study was funded by a University of Warwick Pro-Vice Chancellor (Research) COVID Research Programme Award and supported by the Warwick Health Global Research Priorities.

\section{Declaration of interest}

None.

\section{References}

1 Li Y, Zhao J, Ma Z, McReynolds LS, Lin D, Chen Z, et al. Mental health among college students during the COVID-19 pandemic in China: a 2-wave longitudinal survey. J Affect Disord 2021; 281: 597-604.

2 Wang X, Hegde S, Son C, Keller B, Smith A, Sasangohar F. Investigating mental health of US college students during the COVID-19 pandemic: cross-sectional survey study. J Med Internet Res 2020; 22(9): e22817.

3 Wathelet M, Duhem S, Vaiva G, Baubet T, Habran E, Veerapa E, et al. Factors associated with mental health disorders among university students in France confined during the COVID-19 pandemic. JAMA Netw Open 2020; 3(10): e2025591.

4 Tasnim R, Islam MS, Sujan MSH, Sikder MT, Potenza MN. Suicidal ideation among Bangladeshi university students early during the COVID-19 pandemic: prevalence estimates and correlates. Child Youth Serv Rev 2020; 119: 105703.

5 O'Connor R, Wetherall K, Cleare S, McClelland H, Melson A, Niedzwiedz C, et al. Mental health and well-being during the COVID-19 pandemic: Iongitudinal analyses of adults in the UK COVID-19 mental health \& wellbeing study. Br J Psychiatry 2021; 218(6): 326-33.

6 Gunnell D, Appleby L. Suicide risk and prevention during the COVID-19 pandemic. Lancet Psychiatry 2020; 7(6): 468-71.

7 Leaune E, Samuel M, Oh H, Poulet E, Brunelin J. Suicidal behaviors and ideation during emerging viral disease outbreaks before the COVID-19 pandemic: a systematic rapid review. Prev Med 2020; 141: 106264.

8 Savage MJ, James R, Magistro D, Donaldsons J, Healy LC, Nevill M, et al. Mental health and movement behaviour during the COVID-19 pandemic in UK university students: prospective cohort study. Ment Health Phys Act 2020; 19: 100357.

9 Evans S, Alkan E, Bhangoo JK, Tenenbaum H, Ng-Knight T. Effects of the COVID19 lockdown on mental health, wellbeing, sleep and alcohol use in a UK student sample. Psychiatry Res 2021; 298: 113819.

10 Debowska A, Horeczy B, Boduszek D, Dolinski D. A repeated cross-sectional survey assessing university students' stress, depression, anxiety, and suicidality in the early stages of the COVID-19 pandemic in Poland. Psychol Med [Epub ahead of print] 2 Oct 2020. Available from: https://doi.org/10.1017/ S003329172000392X.

11 Meda N, Pardini S, Slongo I, Bodini L, Zordan MA, Rigobello P, et al. Students' mental health problems before, during, and after COVID-19 lockdown in Italy. J Psychiatr Res 2021; 134: 69-77.
12 Jahrami H, BaHammam A, Bragazzi NL, Said Z, Faris M, Vitiello MV. Sleep problems during the COVID-19 pandemic by population: a systematic review and meta-analysis. J Clin Sleep Med 2021; 17(2): 299-313.

13 Marelli S, Castelnuovo A, Somma A, Castronovo V, Mombelli S, Bottoni D, et al. Impact of COVID-19 lockdown on sleep quality in university students and administration staff. J Neurol 2020; 268: 8-15.

14 Jackson KM, Merrill JE, Stevens AK, Hayes KL, White HR. Changes in alcohol use and drinking context due to the COVID-19 pandemic: a multimethod study of college student drinkers. Alcohol Clin Exp Res 2021; 45(4): 752-64.

15 Tavolacci MP, Wouters E, Van de Velde S, Buffel V, Déchelotte P, Van Hal G, et al The impact of COVID-19 lockdown on health behaviours among students of a French university. Int J Environ Res Public Health 2021; 18(8): 4346.

16 Holmes EA, O'Connor R, Perry VH, et al. Multidisciplinary research priorities for the COVID-19 pandemic: a call for action for mental health science. Lancet Psychiatry 2020; 7(6): 547-60.

17 Smith M. How Young are 'Young People'? And at What Age Does a Person Become 'Old'? YouGov, 2018 (https://yougov.co.uk/topics/politics/articlesreports/2018/03/06/how-young-are-young-people-and-what-age-does-perso [cited 16 Sep 2021])

18 Spitzer RL, Williams JBW, Kroenke K. Quick Guide to PRIME-MD Patient Health Questionnaire (PHQ) PHQ9 and GAD7. Pfizer, 1999.

19 Thakral M, Von Korff M, McCurry SM, Morin CM, Vitiello MV. ISI-3: evaluation of a brief screening tool for insomnia. Sleep Med 2021; 82: 104-9.

20 National Institute for Health. NIDA Quick Screen v1.0. Screening Measure. National Institute on Drug Abuse (https://nida.nih.gov/sites/default/files/pdf/ nmassist.pdf).

21 Osman A, Bagge C, Guitierrez P, Konick L, Kooper BBF. The suicidal behaviours questionnaire-revised (SBQ-R): validation with clinical and nonclinical samples. Assessment 2001; 8(4): 443-54.

22 IBM Corp. IBM SPSS Statistics for Macintosh, Version 27.0. IBM Corp, 2020.

23 Xu S, Ross C, Raebel MA, Shetterly S, Blanchette C, Smith D. Use of stabilized inverse propensity scores as weights to directly estimate relative risk and its confidence intervals. Value Health 2015; 13(2): 273-7.

24 Pezzi A, Cavo M, Biggeri A, Zamagni E, Nanni O. Inverse probability weighting to estimate causal effect of a singular phase in a multiphase randomized clinical trial for multiple myeloma. BMC Med Res Methodol 2016; 16(1): 150.

25 Chowdhury $M$, Turin $T$. Variable selection strategies and its importance in clinical prediction modelling. Fam Med Community Health 2020; 8(1): e000262.

26 Shuster A, O'Brien M, Luo Y, Berner LA, Perl O, Heflin M, et al. Emotional adaptative during a crisis: decline in anxiety and depression after the initial weeks of COVID-19 in the United States. Transl Psychiatry 2021; 11: 435.

27 Vindegaard N, Benros ME. COVID-19 pandemic and mental health consequences: systematic review of the current evidence. Brain Behav Immun 2020; 89: 531-42

28 Xiong J, Lipsitz O, Nasri F, Lui LMW, Gill H, Phan L, et al. Impact of COVID-19 pandemic on mental health in the general population: a systematic review. J Affect Disord 2020; 277: 55-64.

29 Salehinehjad MA, Azarkolah A, Ghanavati E, Nitsche MA. Circadian disturbances, sleep difficulties and the COVID-19 pandemic. Sleep Med 2022; 91: 246-52.

30 Nelsono B, Hartmann JA. Prediction in mental health research and its limits (or why life can only be understood backwards but must be lived forwards). Early Interv Psychiatry 2018; 12(5): 767-70.

31 Reavley $\mathrm{N}$, Jor AF. Prevention and early intervention to improve mental health in higher education students: a review. Early Interv Psychiatry 2010; 4(2): 132-42.

32 Saunders R, Buckman J, Fonagy P, Fancourt D. Understanding different trajectories of mental health across the general population during the COVID-19 pandemic. Psychol Med [Epub ahead of print] 3 Mar 2021. Available from: https://doi.org/10.1017/S0033291721000957.

33 Field A. Survey fatigue and the tragedy of the commons: are we undermining our evaluation practice? Evaluation matters-he take Tō Te Aromatawai. 2020; (6). Available from: https://doi.org/10.18296/em.0054.

34 Office for National Statistics. Coronavirus and Higher Education Students: England, 20 November to 25 November 2020. ONS, 2020
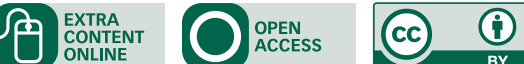